\title{
Self-Presentation in Interracial Settings: The Competence Downshift by White Liberals
}

\author{
Cydney H. Dupree \\ Yale University \\ Susan T. Fiske \\ Princeton University
}

In press at the Journal of Personality and Social Psychology. (CAmerican Psychological Association, 2018. This paper is not the copy of record and may not exactly replicate the authoritative document published in the APA journal. Please cite using the following reference:

Dupree, C. H., \& Fiske, S. T. (in press.) Self-Presentation in Interracial Settings: The Competence Downshift by White Liberals. Journal of Personality and Social Psychology.

\section{Author Notes}

The first author was supported by the National Science Foundation and by Princeton University’s Joint Degree Program in Social Policy.

Correspondence should be addressed to Cydney H. Dupree, Ph.D., School of Management, Yale University, New Haven, CT 06520. E-mail: cydney.dupree@yale.edu. 


\section{Abstract}

Most Whites, particularly socio-political liberals, now endorse racial equality. Archival and experimental research reveals a subtle but reliable ironic consequence: White liberals selfpresent less competence to minorities than to other Whites - that is, they patronize minorities stereotyped as lower status and less competent. In an initial archival demonstration of the competence downshift, Study 1 examined the content of White Republican and Democratic presidential candidates' campaign speeches. Although Republican candidates did not significantly shift language based on audience racial composition, Democratic candidates used less competence-related language to minority audiences than to White audiences. Across five experiments (total $N=2,157$ ), White participants responded to a Black or White hypothetical (Studies 2, 3, 4, S1) or ostensibly real (Study 5) interaction partner. Three indicators of selfpresentation converged: sophistication of vocabulary selected for an assignment, competencerelated traits selected for an introduction, and competence-related content of brief, open-ended introductions. Conservatism indicators included: self-reported political affiliation (liberalconservative), Right-Wing Authoritarianism (values-based conservatism) and Social Dominance Orientation (hierarchy-based conservatism). Internal meta-analyses revealed that liberals—but not conservatives - presented less competence to Black interaction partners than to White ones. The simple effect was small but significant across studies, and most reliable for the self-reported measure of conservatism. This possibly unintentional but ultimately patronizing competencedownshift suggests that well-intentioned liberal Whites may draw on low-status/competence stereotypes to affiliate with minorities.

Keywords: conservatives, liberals, inter-racial versus intra-racial interactions, self-presentation, interaction goals, warmth competence 
Self-Presentation in Interracial Settings: The Competence Downshift by White Liberals

In a popular statement from his keynote address at the 2004 Democratic National

Convention, then-Senator Barack Obama proclaimed, "There's not a Black America and White America and Latino America and Asian America: there's a United States of America." With this, the Black Senator foreshadowed a campaign centered on racial unity and hope, one that would ultimately win him a two-term presidency. As Blacks ascend to prominent leadership positions around the country, journalists, politicians, and laypeople alike have lauded the arrival of a postracial America (Tesler \& Sears, 2010). For many, Obama’s successful, decidedly race-neutral presidential campaign signaled the beginning of a new egalitarian era-much like the one Dr. Martin Luther King referenced years ago — in which minorities can truly be judged "not by the color of their skin, but by the content of their character" (Smith, 2009).

While some followers of recent political events may disagree with the notion that racism is becoming a thing of the past, post-racial sentiments are not entirely without merit. The nation continues to bear witness to the success of people such as Barack Obama, Ursula Burns (the first Black female CEO of a Fortune 500 company), and Sonia Sotomayor (the first Latina Supreme Court justice). The number of Black elected officials has skyrocketed, increasing from an estimated 1,500 in 1970 to over 10,500 in 2011 (Garcia \& Tate, 2013). Not only do Whites show more support for minority leaders, but they also more strongly support social policies directed at leveling the playing field for minorities (Bobo, 2001). At the interpersonal level, recent decades have seen a significant reduction in the expression of explicit prejudice and endorsement of negative stereotypes (Bergsieker, Leslie, Constantine, \& Fiske, 2012; Devine \& Elliot, 1995; Dovidio \& Gaertner, 1986; Fiske, 2002)

Admittedly, these changes in explicit prejudice may to some extent reflect societal norms that reject outward displays of prejudice, possibly prompting Whites regardless of prejudice to merely act egalitarian to avoid rejection (Croft \& Schmader, 2012; Mendes \& Koslov, 2013). In 
support of this possibility, subtler forms of prejudice continue to plague modern Americans

(Dovidio \& Gaertner, 2000; Greenwald, McGhee, \& Schwartz, 1998). Despite White Americans’ more overt support for Blacks, their interactions with minorities thus may still differ from those with other Whites. Despite an increasingly post-racial climate, interpersonal interactions do not change overnight. Whites still show bias in indirect indicators (Banaji \& Heiphetz, 2010; Fazio \& Olson, 2003) and in their nonverbal behavior toward Blacks (Dovidio, Kawakami \& Gaertner, 2002). Such indirect indicators of bias may affect even liberal Whites - those who explicitly value egalitarian ideals by rejecting social inequality and ingroup favoritism.

Stereotypes surrounding minority groups can support a less direct form of bias. Stereotypes depicting racial minorities as lower in competence than Whites have endured over the past century (Bergsieker et al., 2012; Krueger, 1996), remaining visible in multiple media outlets, including television, movies, and news outlets (e.g., Gilens, 1996). Nearly a century ago, Katz and Braly (1933) found that Blacks were most commonly stereotyped as "lazy," "ignorant," and "stupid." Even now Blacks and Latinos are characterized as "low in intelligence" and “ignorant” (Devine \& Elliot, 1995; Krueger, 1996; Weaver, 2007). Recent research suggests that, while Blacks are perceived as relatively American (in contrast to other racial minority groups like Asian-Americans and Latin-Americans), they are still perceived as inferior to Whites (Zou \& Cheryan, 2017).

The current research considers how less direct forms of bias may build on these lowcompetence stereotypes, being perpetuated by Whites', especially White liberals', verbal behavior in interracial contexts. White liberals may indirectly express a patronizing form of bias in their responses to outgroup members by drawing on negative status/competence stereotypes about Blacks. That is, with the best of intentions - seeking to affiliate with a Black interaction partner-White liberals may unwittingly draw on negative stereotypes, dumbing themselves down in a likely well-meaning, "folksy," but ultimately patronizing, attempt to connect with the 
outgroup. This downshift should be specific to competence. White liberals should not present less warmth to a Black interaction partner than they do to a White one, because 1) current racial stereotypes (including race-status associations; Fiske, Dupree, Nicolas, \& Swencionis, 2016) specifically imply less competence; 2) Blacks are not stereotyped as less warm than Whites (Bergsieker, Leslie, Constantine, \& Fiske, 2012, Study 4); and 3) White liberals are theoretically less racist and more motivated than conservatives to affiliate with Blacks, so they should not treat Blacks as less worthy of affiliation (less warm) than Whites. White conservatives, on the other hand, should be less motivated to affiliate interracially, so they would not bother to match themselves to their stereotypic expectancies about their outgroup partners in an attempt to get along. As such, we predict that White liberals (but not White conservatives) will present significantly less competence to a Black interaction partner than to a White one.

\section{Impression Management: The Role of Stereotypes}

This examination of Whites' self-presentation to ingroup or outgroup interaction partners begins with two central dimensions of social perception: warmth and competence. In daily social interaction, people strive to come across as both trustworthy (warm) and respect-worthy (competent). The two dimensions of warmth and competence dictate how people present themselves and how they evaluate others (Fiske, Cuddy, \& Glick, 2007; Leary, 1995; Nezlek, Schutz, \& Sellin, 2007; Wojciszke, 2005). The warmth dimension reflects other-profitable intent—sociality (friendliness) and morality (trustworthiness, sincerity) (Abele et al., 2016; Peeters, 2001). Warmth follows from cooperative interdependence. The competence dimension reflects self-profitable traits—capability (skill, intelligence) and agency (efficacy, assertiveness) (Abele et al., 2001; Peeters, 2001). Competence follows from perceived status. These two dimensions, warmth and competence, consistently underlie person perception at the individual and group level (Abele \& Wojciszke, 2007; Fiske, Cuddy, Glick \& Xu, 2002; Russell \& Fiske, 2008; Wojciszke, 1994; Wojciszke, Bazinska, \& Jaworski, 1998). 
People aim to appear warm or competent by displaying certain behaviors that they believe will elicit these attributions from others (Jones \& Pittman, 1982). They smile and laugh at parties to gain liking; they subtly mention accomplishments during interviews in hopes of garnering respect. Engaging in such self-presentation with the goal of eliciting certain attributions from others constitutes impression management (Goffman, 1959; Jones \& Pittman, 1982; Leary, 1995; Schlenker \& Pontari, 1973).

One principle of impression management is expressing similarity: reciprocal warmth, shared opinions, and comparable accomplishments (Lydon, Jamieson, \& Zanna, 1988; Rosenfeld, Giacalone, \& Riordan, 1995; Wayne \& Ferris, 1990). One way in which people express similarity is by matching their partners' expectations, going along with what they believe their partner expects in order to get along (Sinclair, Lowery, Hardin, \& Colangelo, 2005; Swencionis \& Fiske, 2016). Absent detailed information about their partner, people may also express similarity by matching their own expectations about their partner, going along with their initial impressions in order to get along. Among these expectancies are category-based stereotypes. Well-intentioned impression managers may try to match even their negative stereotype of an outgroup member, in efforts to "get on their level." Getting along with a lowerstatus group may entail presenting oneself as less competent or lower in status - that is, "getting down with the people."

Intergroup self-presentation goals also include avoiding negative meta-stereotypes - that is, the other's expectations about the self. People are aware of the stereotypes applied to their own groups, and this has implications for impression management in intergroup interactions. For example, perceptions of Blacks and Latinos as unintelligent (Krueger, 1996; Shelton \& Richeson, 2006) and Whites as intolerant (Krueger, 1996; Vorauer, Main, \& O’Connell, 1998) can lead to divergent impression management goals in interracial contexts. When considering the respective impression management goals of Whites and minorities in an interracial context, 
Bergsieker and colleagues (2010) predicted and found that Whites' and minorities' goals

diverged. In interracial contexts, Whites sought to be seen as more likeable and moral (warm)

than minorities did, so they engaged in ingratiation more than minorities did. In contrast, minorities sought to be seen as more respect-worthy (competent) than Whites did, so they engaged in self-promotion more than Whites did (Bergsieker, Shelton, \& Richeson, 2010). These findings contribute to a growing line of research indicating that Whites and racial minorities have divergent perspectives in interracial interactions, undermining expectations and experiences (Bergsieker et al., 2010; Richeson \& Shelton, 2007; Shelton \& Richeson, 2006).

\section{Interracial Interactions: Socio-political Attitudes Predict Positive Intentions}

High-status group members are aware that low-status groups can see their group as racist (Vorauer, Hunter, Main, \& O’Connell, 2000; Vorauer, Main, \& O’Connell, 1998)—or cold, more generally; this may be why, when interacting with minorities, Whites wish to appear likeable (Bergsieker, Shelton, \& Richeson, 2012). However, some Whites may feel more concerned than others about how they appear in the eyes of minorities. Whites with the most egalitarian attitudes might be those who most desire to connect with minorities - but still lack the skills to act on their well-intentioned beliefs. Whites who do have concerns about appearing nonprejudiced tend to feel more anxiety and less enjoyment in interracial contexts (Shelton, 2003; Shelton, West, \& Trail, 2010; Vorauer, Main, \& O’Connell, 1998).

More generally, socio-political attitudes are linked with Whites' intergroup prejudice and discrimination (Ho, Sidanius, Cuddy, \& Banaji, 2013; Jost, Banaji, \& Nosek, 2004; Knowles, Lowery, Hogan \& Chow, 2009; Kteily, Cotterill, Sidanius, Sheehy-Skeffington, \& Bergh, 2014; Thompsen, Green, \& Sidanius, 2008). As such, those who describe themselves as lowest in socio-political conservatism (i.e., the most liberal) may be most likely to want to affiliate and therefore adjust their responses in outgroup (versus ingroup) settings.

These socio-political attitudes doubtless affect the dynamics of intergroup interactions, 
but to our knowledge, no research has investigated how such attitudes relate to self-presentation in interracial settings. The current research examines self-reported conservatism (i.e., overall political ideology, ranging from "extremely liberal" to "extremely conservative") and two individual-difference variables that relate to a variety of socio-political attitudes and behaviors: Right Wing Authoritarianism (RWA; Altemeyer, 1981, 1988) and Social Dominance Orientation (SDO; Pratto, Sidanius, Stallworth, \& Malle, 1994). Past research has shown that these wellvalidated measures tend to correlate significantly with self-ratings of liberalism; therefore, we refer to those who are low in these measures as "liberal" and those who are high in these measures as “conservative.” As described, however, by Duckitt's (2001) Dual Process Model (DPM) perspective, although both can predict the expression of prejudice toward different groups, RWA and SDO operate independently of each other. Each reflects a distinctive set of socio-political beliefs, respectively values-based and hierarchy-based conservatism.

\section{Right-Wing Authoritarianism: Values-based Conservatism.}

RWA, a measure of values-based conservatism, expresses a motivation to protect the ingroup against value threats (Asbrock, Christ, Duckitt, \& Sibley, 2012). Over a half-century’s worth of research has solidified RWA as a basic dimension that reflects individuals' social and political attitudes (Authoritarianism: Adorno, Frenkel-Brunswick, Levinson, \& Sanford, 1950; RWA: Altemeyer, 1981, 1996). Though this measure has traditionally been treated as a unidimensional construct, it was originally conceptualized as involving three separate but related components: 1) authoritarian submission-deference to those considered to be legitimate authority figures; 2) authoritarianism aggression—sanctioned punitive responses toward wrongdoers and deviants; and 3) conventionalism — adherence to the norms and values established by authority and tradition (Altemeyer, 1988, 1996, 1998). Those higher in RWA tend to value traditionalism, aggress against those who violate ingroup norms, and submit to existing authorities, seeking collective security and social cohesion within the ingroup. In contrast, those 
lower in RWA value independence and autonomy from the ingroup, rejecting traditional norms and hostility to outsiders. Therefore, Whites lowest in RWA (i.e., values-based liberals) should be most amenable to interacting with minorities, while those highest in RWA (i.e., values-based conservatives) most avoid outgroup contact.

\section{Social Dominance Orientation: Hierarchy-based Conservatism.}

SDO, a measure of hierarchy-based conservatism, expresses a motivation to achieve group-based dominance or superiority over outgroups (Ho et al., 2015; Pratto et al., 1994). Whites higher in SDO value the maintenance of group-based hierarchies, such that higher-status groups can remain on top, and lower-status groups can remain on the bottom. In contrast, Whites lower in SDO express more altruistic social concern around outgroups, favoring a less hierarchical and more egalitarian society. Therefore, while White hierarchy-based conservatives avoid various outgroup members, White hierarchy-based liberals should be less threatened by outgroup members, possibly prompting strategies aimed at affiliation.

Despite these well-documented differences in the motivational theories that underlie RWA and SDO — and the personality constructs that relate to each socio-political attitude — the current work is the first to examine whether and how SDO and RWA relate to Whites' verbal behaviors in inter- versus intra-group settings.

\section{Overview of Experiments}

Building on two central dimensions of social perception, the following studies use experimental and archival analyses to explore Whites' self-presentation to a Black (versus White) interaction partner. In seeking to affiliate with Blacks, White liberals (those low in selfreported political conservatism, values-based conservatism, or hierarchy-based conservatism) may draw on minority-incompetence stereotypes to do so, presenting less competence to a Black interaction partner than to a White one. White conservatives, in contrast, should be less likely to engage in a competence downshift, as they are less motivated to affiliate with racial minorities. 
The primary hypothesis, therefore, is that White liberals (but not White conservatives) will present significantly less competence to a Black interaction partner than to a White one.

Because competence is only one of the two fundamental dimensions of person and group perception, the studies also measure Whites' self-presentation of warmth. However, White liberals should not present less warmth to a Black partner than a White partner. The current work makes no such predictions for self-presentation of warmth for two reasons. First, while Blacks are still stereotyped as lower in status and competence than Whites, they are not stereotyped as colder than Whites. (Blacks may even be seen as more warm than competent, due to the ambivalent nature of many outgroup stereotypes; Bergsieker et al., 2012, Study 4.) Second, White liberals explicitly endorse interracial contact more than White conservatives do. Therefore, White liberals should be equally affiliative (warm) — if not more so — to outgroup versus ingroup partners.

Five studies used archival and experimental methodologies to explore White liberals' self-presentation of competence and warmth with a Black (versus White) interaction partner. In an initial archival demonstration of the competence downshift, Study 1 examined the content of White Republican and Democratic presidential candidates' campaign speeches. Archival data demonstrated that Democratic_-versus Republican—White presidential candidates have displayed a competence downshift over recent decades, using significantly fewer words related to agency or power (and more words related to affiliation and communality) to audiences composed mostly of minorities than to mostly-White audiences (Study 1). Initial experimental investigations used hypothetical vignettes that measure self-presentation through word selection, including competence- or warmth-focused scenarios (Studies $2-4$ ). The final study moved to a more ecologically valid test in which White participants introduced themselves to ostensibly real interaction partners, measuring self-presentation through text-based analysis of participants' open-ended responses (Study 5). See Table 1 for a summary of all studies. 
Table 1

Summary of studies Paradigm and study

Dependent variables

Conservatism measures

Archival study: Presidential candidate campaign speeches

Study $1(N=74 ; n=74)$
Percentage agency- and power-related words

Word selection (book review), interaction goals

Word selection (book review), interaction goals

Trait selection (introduction), interaction goals

Word selection (book review), interaction goals
Political party

Self-reported conservatism

Self-reported conservatism, SDO, RWA

Self-reported conservatism, SDO, RWA

Self-reported conservatism, RWA

Presumably-real interaction partner:

Online introduction Study $5(N=743 ; n=652)$

Percentage agency- and power-related words, trait selection,

Self-reported conservatism, interaction goals, anticipated partner evaluations

Note. For each study, the table indicates the total number of participants $(N)$ and the number of participants included in the analy ses $(n)$. Study $\mathrm{S} 1$ is described in the Supplemental Material available online (see Additional Methods and Results). 


\section{Study 1: Archival Analysis of Presidential Campaign Speeches}

Both within and outside the realm of psychology, "words do the work of politics"

(Graham, Haidt, \& Nosek, 2009). The political realm provided the ideal context for an initial test of liberals enacting a competence downshift in a real-world setting. Here, Democrats constitute the liberals, whereas Republicans constitute the conservatives. This provided an opportunity to directly compare self-presentation from group members who are more conservative (i.e., probably high in self-reported, values- or hierarchy-based conservatism) to those who are more liberal (i.e., probably low in self-reported, values-, or hierarchy-based conservatism). Varying audience race entailed examining presidential campaign speeches that were addressed to mostlyWhite or mostly-minority audiences. We predicted that Democratic presidential candidates would engage in a competence downshift. Democratic candidates' campaign speeches given to minority audiences should be less competence-focused than comparable speeches directed to mostly White audiences. As conservatives are less involved with outgroup affiliation, Republican candidates should be less likely to engage in this self-presentational response: That is, competence presented should not significantly vary depending on the racial composition of the audience.

\section{Method}

These hypotheses were tested through content analysis of 74 speeches delivered by the primary White Republican and Democratic presidential candidates over the course of four separate presidential campaigns. Half of these speeches were delivered to an audience composed primarily of minorities; each of these mostly-minority audience speeches was matched with a comparable speech given to a mostly-White audience. Text analysis determined differences in competence and warmth presented to White or minority audiences for each candidate. Thus this study involved a comparative analysis of the speeches delivered to White versus minority audiences, by Republican versus Democratic presidential candidates, across four separate 
presidential campaigns over the past 25 years.

Presidential campaign speeches were obtained from a number of online archives that included speeches dating back to the 1992 presidential campaign. Analyses examined speeches delivered only by nominees who won their party's primary election and moved on to run against the other party's nominee for the presidency. Because the study seeks to examine a competence downshift demonstrated by White liberals, it did not include speeches delivered by a Black candidate (i.e., Barack Obama). The study also avoided potential gender effects by excluding speeches delivered by a female candidate (i.e., Hillary Clinton). It also avoided candidacy speeches by sitting presidents who ran for re-election. (Such candidates could view themselves as higher in status than those candidates who were not or never had been commander-in-chief, introducing a potential confound.)

The number of speeches delivered to majority-minority audiences were much fewer than those delivered to majority-White audiences. As such, the sample size was determined by the number of speeches to delivered minority audiences that were available in online archives. Multiple methods were used to determine whether a speech could be categorized as minorityaudience. First, searches looked to the nature of the conference or organization receiving the presidential candidate. Speeches delivered to organizations that involve a particular minority group (e.g., the National Association for the Advancement of Colored People, Republican National Hispanic Assembly) or directly address issues of diversity (e.g., National Urban League, Rainbow Coalition) were categorized as minority-audience speeches. Secondly, searches turned to the context of the speeches to determine the likely racial composition of the audiences on the receiving end. Speeches were placed into minority-audience category if they were delivered at events that commemorated a landmark occasion for a minority group (e.g., $40^{\text {th }}$ anniversary of Dr. Martin Luther King Jr.'s death, Cuban Independence Day). Lastly, searches looked to the location at which the speeches were delivered. They were minority classified if 
speeches were delivered to a historically Black college or university (HBCU), at a school comprising primarily minority students, or in a town with a majority-minority population.

Searches also categorized an audience as minority if a speech was delivered at a mostly-minority Baptist event (e.g., National Baptist Convention) or at a historically Black Baptist church, as over $90 \%$ of all members of the historically Black Protestant church (of which Baptist is the largest denomination) are Black (Pew Research Center, 2014). These criteria admittedly combine Black and Latino audiences, but this compromise assumes that White stereotypes of Black and Latino competence are similar (Fiske et al., 2002), and it affords more statistical power. This process resulted in the collection of 23 speeches delivered to minority audiences by Democratic candidates and 14 delivered to minority audiences by qualifying Republican candidates over the past two decades.

After collecting all available speeches delivered by eligible presidential candidates to mostly-minority audiences, each was then paired with a comparable speech to a majority-White audience. For each minority-audience speech, a White audience speech was found that closely resembled the context of its match in several different ways. Speeches were matched on topic of discussion (e.g., a speech on a civic anniversary, Brown versus Board of Education, was matched with a speech on a cause-based civic holiday, Earth Day), focus of organization (e.g., a speech given at a Hispanic Small Business Roundtable discussion was matched with a speech given at a Small Business Roundtable discussion), size of the audience (e.g., a speech given at an HBCU was matched with a speech given at a mostly-White college of similar size), and approximate timing in the campaign. This pairing process resulted in a total of 74 speeches delivered to mostly-White or mostly-minority audiences by Republican or Democratic candidates over the course of four separate campaigns (see Appendix A for a complete list of paired speeches.) ${ }^{1}$

\footnotetext{
${ }^{1}$ Certain presidential candidates were excluded from this analysis because they delivered few or no speeches directly to minority audiences or focused on minority issues. This includes Donald
} 
Having identified Republican and Democratic candidates and obtained transcribed speeches delivered to predominantly-White or predominantly-minority audiences, analyses then examined candidates' self-presentation of warmth and competence. Linguistic Inquiry and Word Content Software (LIWC; Pennebaker et al., 2007) was used to determine the word counts related to the dimensions of competence or warmth in each speech.

\section{Results}

Content of speeches. Quantitative content-analysis of texts has long been considered the most objective approach to linguistic data (Silverman, 1993). Linguistic Inquiry and Word Content Software (LIWC; Pennebaker, Booth, \& Francis, 2007) analyzed the content of the introductions provided by participants, determining the frequencies with which words related to competence and words related to warmth appeared in each introduction.

Competence and warmth dictionaries were created to measure participants' selfpresentation in participants' introductions. The competence dictionary was derived from published lists of agentic words and from LIWC's power dictionary, which includes 518 words relevant to status, dominance, and social hierarchy (e.g., assertive, competitive; Gaucher, Friesen, \& Kay, 2011; Pennebaker, Booth, Boyd, \& Francis, 2015; Rudman \& Kolinski, 2000). The warmth dictionary was derived from published lists of communal words and from LIWC's affiliation dictionary, which includes 248 words that reference others (e.g., supportive, compassionate; Gaucher, Friesen, \& Kay, 2011; Pennebaker, Booth, Boyd, \& Francis, 2015; Rudman \& Killianski, 2000). ${ }^{2}$ Using LIWC, each text was then given a competence self-

Trump (elected 2016), who, according to our data collection efforts, delivered no speeches directly to or focusing on minority groups (a possible exception includes an August 2016 speech focused on immigration). This also excludes George W. Bush (elected 2000), whose pre-election remarks were largely unavailable online. Those that were available did not address minority audiences or minority-focused occasions or policies.

${ }^{2}$ Sociality (communality and affiliation) commonly corresponds to the warmth dimension, while agency and power correspond to the competence dimension (Abele et al., 2016; Fiske, Cuddy, \& Glick, 2007). The primary distinction between communality/affiliation and agency/power is that 
presentation score and a warmth self-presentation score based on the percentage of times words from the corresponding dictionaries occurred within the text. Analyses treated competence and warmth scores separately. Each self-presentation score was residualized off the other. These standardized residuals were analyzed.

Presidential candidates' overall word usage. On average, presidential candidates' speeches included 2670.62 words $(S D=1048.91)$, with an average of 18.44 words per sentence $(S D=2.42)$. Turning to the dependent variables, percentages of competence- $(M=5.08, S D=$ 0.97$, skew $=0.49$, kurtosis $=0.03)$ and warmth-related $(M=5.49, S D=1.23$, skew $=0.32$, kurtosis $=0.27$ ) words used in speeches were relatively normal. Because all speeches were delivered by male presidential candidates, preliminary analyses did not include tests for gender effects.

Warmth and competence self-presentation scores were moderately correlated $(r=-.35, p$ $<$.001). In this and all studies, warmth and competence self-presentation measures were slightly to moderately correlated, in either the positive or negative direction. Positive correlations likely reflect a halo effect; people tend to think of others (or wish themselves to appear) as generally superior or generally inferior (Thorndike, 1920). Negative warmth/competence correlations likely reflect a compensation effect; people who wish to appear high in one dimension actively downplay self-presentation on the opposing dimension (Holoien \& Fiske, 2013). To avoid shared variance between self-presentation of warmth and self-presentation of competence, standardized residuals of each self-presentation variable were computed and analyzed across studies. These residuals represented self-presentation of warmth, partialing out the variance accounted for by self-presentation of competence, and vice versa. See Table 2 for descriptive statistics of and correlations between self-presentation and conservatism measures across studies.

the former concern profitability to others, while the latter concern profitability to self (Abele \& Wojciszke, 2007). 
Table 2

Means, Standard Deviations, and Correlations Between Variables in Studies $1-5$

\begin{tabular}{|c|c|c|c|c|c|c|c|c|c|}
\hline Variable & Study & Conservatism & SDO & RWA & Competence & Warmth & $M$ & $S D$ & Range \\
\hline \multirow{5}{*}{$\begin{array}{l}\text { Self-reported conservatism } \\
\text { (Conservatism) }\end{array}$} & Study 1 & & - & - & - & - & - & - & - \\
\hline & Study 2 & & - & - & $-.15 \dagger$ & -.09 & 4.85 & 1.72 & $1-7$ \\
\hline & Study 3 & & $.47 * * *$ & $.66 * * *$ & -.07 & .06 & 3.25 & 1.77 & $1-7$ \\
\hline & Study 4 & & $.45^{* * * *}$ & $.61 * * *$ & -.04 & $.12 *$ & 3.08 & 1.63 & $1-7$ \\
\hline & Study 5 & & $.51 * * *$ & $.67 * * *$ & .01 & .06 & 3.43 & 1.83 & $1-7$ \\
\hline \multirow{5}{*}{$\begin{array}{l}\text { Social Dominance Orientation } \\
\text { (SDO) }\end{array}$} & Study 1 & & & - & - & - & - & - & - \\
\hline & Study 2 & & & - & - & - & - & - & - \\
\hline & Study 3 & & & $.57 * * *$ & $-.14 * *$ & -.03 & 39.28 & 21.12 & $16-108$ \\
\hline & Study 4 & & & $.52 * * *$ & .03 & .08 & 36.92 & 19.20 & $16-104$ \\
\hline & Study 5 & & & $.51 * * *$ & .00 & .01 & 36.03 & 21.22 & $16-112$ \\
\hline \multirow{5}{*}{$\begin{array}{l}\text { Right-Wing Authoritarianism } \\
\text { (RWA) }\end{array}$} & Study 1 & & & & - & - & - & - & - \\
\hline & Study 2 & & & & - & - & - & - & - \\
\hline & Study 3 & & & & $-.14 * *$ & .07 & 63.60 & 35.84 & $20-168$ \\
\hline & Study 4 & & & & $-.12 *$ & $.17 * *$ & 57.35 & 34.18 & $20-164$ \\
\hline & Study 5 & & & & .03 & $.08 \dagger$ & 63.18 & 35.80 & $20-172$ \\
\hline \multirow[t]{5}{*}{ Competence } & Study 1 & & & & & $-.35 * *$ & 5.08 & 0.97 & $3.49-7.65$ \\
\hline & Study 2 & & & & & $.31 * * *$ & 4.80 & 0.30 & $4.06-5.51$ \\
\hline & Study 3 & & & & & $.23 * * *$ & 4.75 & 0.30 & $3.75-5.51$ \\
\hline & Study 4 & & & & & $-.43 * * *$ & 6.39 & 0.58 & $4.81-7.84$ \\
\hline & Study 5 & & & & & $-.14 * * *$ & 1.85 & 1.97 & $0-10.87$ \\
\hline \multirow[t]{5}{*}{ W armth } & Study 1 & & & & & & 5.49 & 1.19 & $2.82-9.11$ \\
\hline & Study 2 & & & & & & 4.43 & 0.40 & $3.32-5.54$ \\
\hline & Study 3 & & & & & & 4.66 & 0.57 & $2.71-5.54$ \\
\hline & Study 4 & & & & & & 5.15 & 0.49 & $3.80-6.42$ \\
\hline & Study 5 & & & & & & 4.92 & 3.47 & $0-27.94$ \\
\hline
\end{tabular}


Self-presentation. Recall that the main prediction suggests that Democrats should present less competence to minority audiences than to White audiences. No such downshift in Democrats' self-presentation of warmth should emerge based on the race of the audience. Finally, Republican self-presentation of competence should not significantly differ based on race of audience because they should be less motivated to match stereotypic expectations of minority audience in attempts to affiliate. Competence and warmth word usage were examined separately.

Competence word usage. Republicans' and Democrats' competence self-presentation scores were submitted to a 2 (Speaker Party: Republican, Democrat) $\times 2$ (Audience Race: White, minority) between-subjects ANOVA. A significant main effect of audience race emerged: Politicians generally used fewer competence-related words with minority audiences $(M=-.21$, $S E=.15,95 \%$ Confidence Interval $(\mathrm{CI})=[-.51, .10])$ than they did with White audiences $(M=$ $.38, S E=.15,95 \% \mathrm{CI}=[.08, .69], F(1,70)=7.54, p=.008, \eta_{\mathrm{p}}^{2}=.097$. A significant main effect of speaker party also emerged: Democrats generally used fewer competence words $(M=-.28, S E$ $=.13 ; 95 \% \mathrm{CI}=[-.54,-.01])$ than $\operatorname{did}$ Republicans $(M=.45, S E=.17,95 \% \mathrm{CI}=[.12, .79])$, $F(1,70)=11.49, p=.001, \eta_{\mathrm{p}}^{2}=.141$

The two-way interaction did not reach significance, $F(1,70)=0.04, p=.848, \eta_{\mathrm{p}}^{2}=.001$. The sample size was ultimately limited to the number of transcribed speeches delivered to mostly-White or mostly-minority audiences by Democratic or Republican presidential candidates. The inability to increase sample sizes makes it difficult to reliably interpret the twoway interaction. As such, with that caution, analysis moved forward with more focused, simpleeffects tests of the hypothesis, analyzing the effect of audience race on Democrats' and Republicans' competence word usage.

Democrats' speeches addressed to majority-minority audiences $(M=-.59, S E=.19,95 \%$ $\mathrm{CI}=[-.96,-.22])$ contained significantly fewer competence-related words than those addressed to majority-White audiences $(M=.04, S E=.19,95 \% \mathrm{CI}=[-.33, .41], F(1,70)=5.70, p=.020$, 
$\eta_{\mathrm{p}}^{2}=.075$ (Figure 1). Republicans' speeches delivered to mostly-minority audiences $(M=.18, S E$ $=.24,95 \% \mathrm{CI}=[-.30, .66])$ contained slightly fewer competence words as those delivered to mostly-White audiences $(M=.73, S E=.24,95 \% \mathrm{CI}=[.25,1.20])$; this difference did not reach significance, $F(1,70)=2.62, p=.110, \eta_{\mathrm{p}}^{2}=.036$.

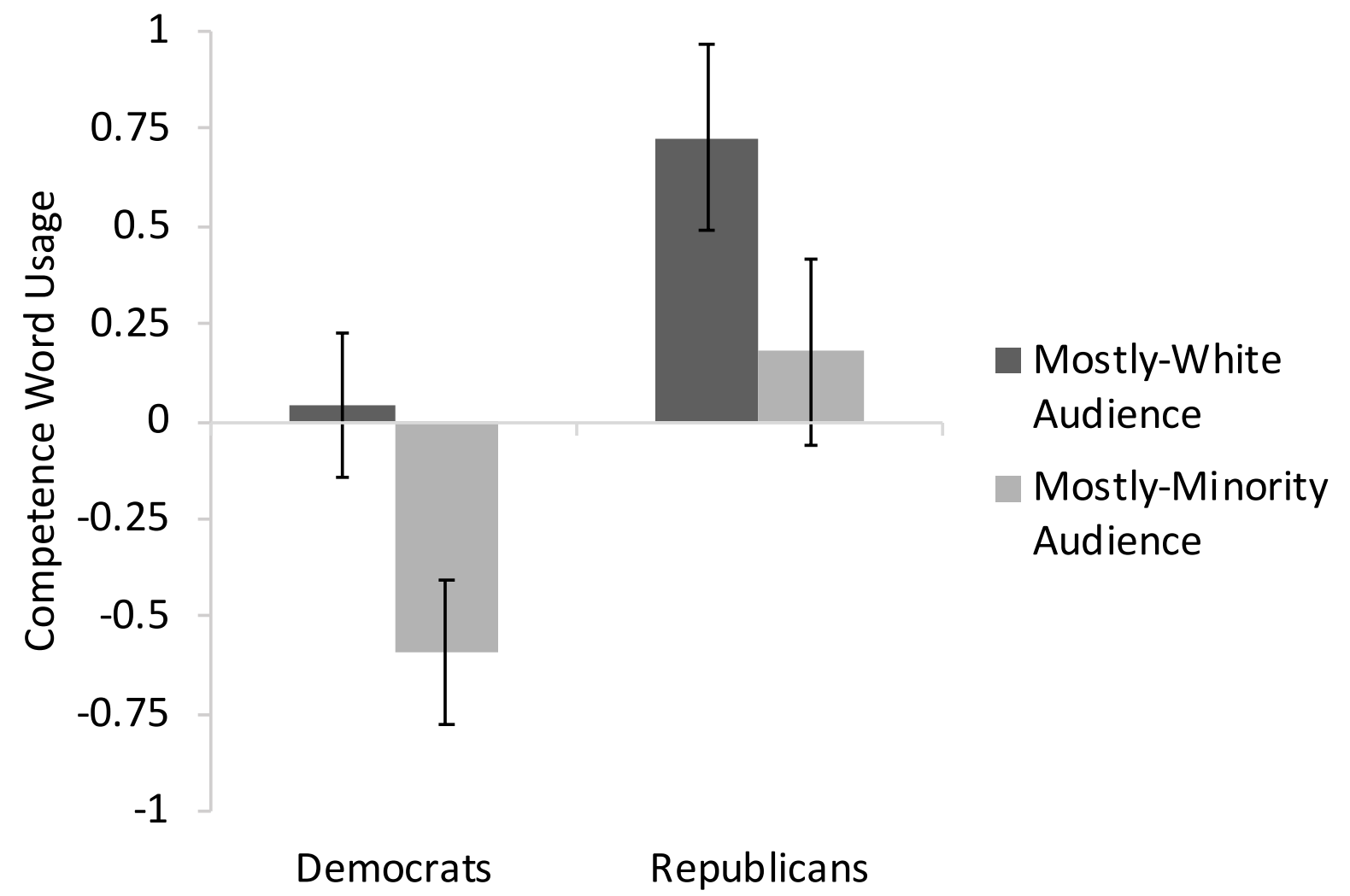

Figure 1. Frequency of competence-related words (standardized residuals) used in Democratic and Republicans' presidential candidates' speeches as a function of audience race. Error bars indicate standard error. 
Warmth word usage. A significant main effect of speaker party emerged: Democrats tended to use more warmth words $(M=.23, S E=.14,95 \% \mathrm{CI}=[-.05, .51])$ than did Republicans $(M=-.38, S E=.18,95 \% \mathrm{CI}=[-.75,-.01]), F(1,70)=6.92, p=.011, \eta_{\mathrm{p}}^{2}=.090$ (Figure 2). No other main effects or interactions reached significance ( $p s>.547)$.

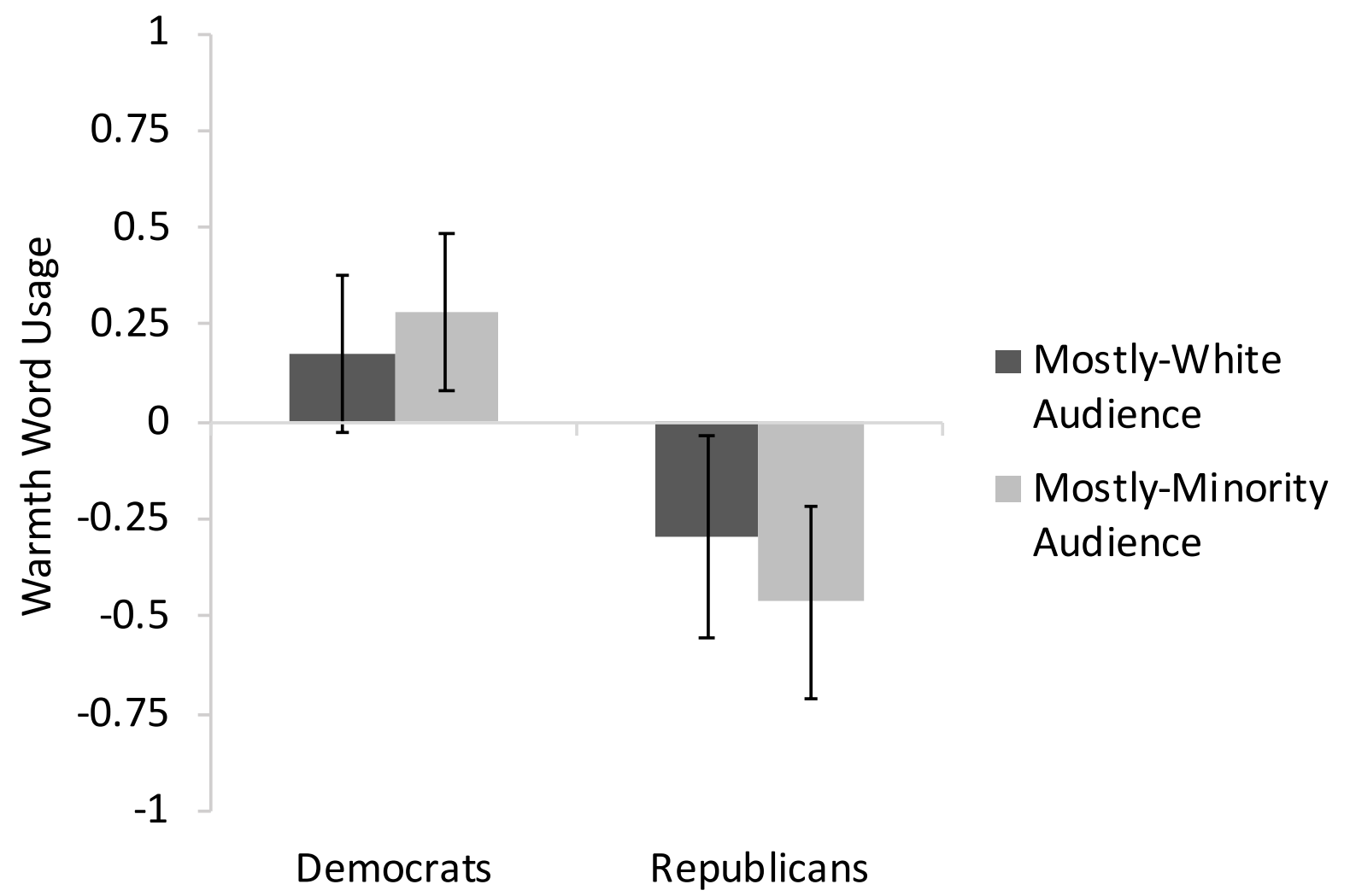

Figure 2. Frequency of warmth-related words (standardized residuals) used in Democratic and Republican presidential candidates' speeches as a function of audience race. Error bars indicate standard error.

\section{Discussion}

Using a comparative analysis of political speeches delivered to mostly White versus mostly minority audiences by both Democrats and Republicans, Study 1 provides initial evidence of liberals enacting a competence downshift in a real-world setting. Presidential candidates who stand for the liberal political party expressed significantly less competence- 
using fewer words related to power and agency — to minority audiences than to White audiences.

Those who stood for the conservative party also tended to use fewer competence-related words with minority audiences. Indeed, the main effect of audience race on politicians' competence word usage reached significance; all politicians tended to use fewer competencerelated words with mostly-minority audiences than with mostly-White ones. Conservatives may show the beginnings of a competence downshift in this case because, in a political context, even conservatives wish to affiliate with their minority audience. (As such, this could constitute a challenging test of the hypothesis.) The conservatives' competence downshift, however, did not reach significance. This may be a function of statistical power-again, conservatives rarely addressed minority audiences or minority-focused issues. Ultimately, though, this finding supports the original hypothesis: liberals demonstrate a competence downshift when responding to Black (versus White) others.

This shift in verbal behavior may not reflect a self-presentational strategy. Using fewer competence-related words may not make one appear less competent, and White Democrats may not be aware that they enact a competence downshift. However, this effect—significant only among Democrats - provides initial evidence that Whites who may be more affiliative toward Blacks alter their verbal responses toward them in a way that matches negative stereotypes. Despite the patronizing behavior that they enact, these liberal candidates may hold more goodwill toward minorities. They tend to endorse policies that attend to reduce social inequality, and they show up more for minority voters. However, the reduction in competence shown to minority audiences provides ecologically valid evidence of likely-unintentional but ultimately patronizing behavior enacted by egalitarian Whites toward minorities. Indeed, this behavior has been occurring for at least 20 years in the political realm.

\section{Study 2: A Book Review (Students)}


Study 1 provided initial evidence of a competence downshift in a real-world setting:

Democratic, but not Republican, presidential candidates presented significantly less competence to a majority-minority audience than to a majority-White one. The following 4 experiments further explore this effect, including multiple indicators of conservatism, multiple partner race manipulations, and multiple self-presentation measures. In an initial experimental test of liberals' competence downshift, a hypothetical social scenario tests whether liberal White students (those who are low in self-reported conservatism) will present less competence to a Black interaction partner than they do to a White one.

\section{Method}

Participants and design. Undergraduate students who identified as White were recruited via e-mail by Princeton University’s Survey Research Center. One hundred and fifty-three undergraduate students (100 women and 53 men, average age $=20.1)$ participated in exchange for the chance to be entered into a lottery to receive \$25 Amazon.com gift cards. Participants were randomly assigned to an ingroup or outgroup partner condition in this two-cell betweensubjects design (Partner race: White, Black). Sample size was determined by the number of participants that completed the questionnaire before the end of the academic term.

Procedure. Following Holoien and Fiske's (2013) online procedure, participants began the survey by reading the following scenario:

Imagine that you have recently joined a book club. Lately you have wanted to do more reading, and a book club seems like a good way to meet new people and discover new books. Before each meeting, one person writes a brief email to the club secretary, Emily (Lakisha), describing his or her thoughts about the book. Emily (Lakisha) will then distribute the review to the group. This month, you have been assigned to e-mail Emily (Lakisha) with a review of this month's book.

The name of the club secretary varied dependent on the condition to which the participant 
was randomly assigned: White or Black interaction partner, respectively Emily (a stereotypically White name) or Lakisha (a stereotypically Black name). ${ }^{3}$

After reading this hypothetical scenario, all participants completed an instructional check to ensure that they read it. This check consisted of three questions regarding the book club scenario. If any question was answered incorrectly, then the scenario was displayed once again, and participants were instructed to read the instructions carefully to ensure that they understood.

Upon passing the instructional check, participants saw a list of 24 words to use in their hypothetical e-mail to the book club secretary. These words were pretested to indicate the user's self-presentation of warmth or competence (Holoien \& Fiske, 2013). Each word had a warmth or competence self-presentation rating, based on responses from a separate sample of 60 participants recruited on Amazon's Mechanical Turk. These pretesters scored each word on how warm and competent a person using these words in an e-mail would appear (rather than the warmth and competence conveyed by the definition of each word). Warmth was conveyed by positivity, and competence was conveyed by vocabulary sophistication. The final list consisted of six words in each of four categories: high warmth/high competence (e.g., euphoric), high warmth/low competence (e.g., happy), low warmth/high competence (e.g., melancholy), and low warmth/low competence (e.g., sad). Participants viewed this list of 24 pretested words and selected 12 to include in their e-mail to the book club secretary.

A warmth self-presentation score and a competence self-presentation score for each participant was derived from their word selections by weighing each selected word by the warmth and competence ratings that it received in the initial pretest. For example, if a participant

\footnotetext{
${ }^{3}$ Prior labor market research has identified these names as "White-sounding" and "Blacksounding", respectively, based on name frequency data collected from birth certificates and pilot data (Bertrand \& Mullainathan, 2004). An online pretest $(n=46)$ revealed that "Lakisha" is viewed as more stereotypically Black than stereotypically White; the converse held true for "Emily" ( $p$ s <.001). However, participants did not respond to a target race stimuli check in studies featuring this vignette paradigm (Studies 2-4).
} 
selected the word "great," that selection received a warmth rating of 5.72 and a competence rating of 3.97 (see Appendix B in Supplemental Materials for all ratings). The averaged warmth and competence ratings of all 12 words selected by each participant served as the primary measure.

As an exploratory measure, participants' explicit, self-reported interaction goals were assessed following the word selection task. Participants rated the extent to which they wished to meet warmth- or competence-related interaction goals when responding to the book club secretary. Specifically, they rated on a 100 -point scale $(1=$ not at all, $100=$ very much $)$ at 10 point increments the extent to which they wanted to appear: kind, fair, intelligent, likeable, competent, open-minded, and like a literary expert. A scale of participants' competence-related interaction goals was created by averaging responses to competence-related items (intelligent, like a literary expert; $\alpha=.71$ ), and a scale of participants' warmth-related interaction goals was created by averaging responses to warmth-related items (kind, fair, likeable, open-minded; $\alpha=$ .81). Finally, participants provided demographic information, including self-reported conservatism $(1=$ extremely liberal, 7 = extremely conservative $)$.

\section{Results}

Preliminary analyses revealed no significant main effects or interactions as a function of participant gender. Therefore, all following analyses collapsed across participant gender. Warmth and competence ratings were slightly correlated $(\mathrm{r}=.37, \mathrm{p}<.001)$, mirroring the halo effect found by Holoien and Fiske (2013). Standardized residuals of each self-presentation variable were computed and analyzed across studies. These residuals represented selfpresentation of competence, partialing out the variance accounted for by self-presentation of warmth, and vice versa.

Self-presentation: Word selections. Warmth and competence self-presentation scores were analyzed separately. 
Competence of word selections. A main effect of partner race emerged: overall, participants presented less competence to a Black interaction partner than to a White one, $\beta=-$ $.17,95 \% \mathrm{CI}=[-.33,-.02], t(149)=-2.17, p=.031$. No other main effects or interactions reached significance $(p s>.405)$.

The Conservatism $\times$ Partner Race interaction did not reach significance $(\beta=.07,95 \% \mathrm{CI}$ $=[-.09, .23], t(149)=0.85, p=.405)$, as such simple effects must be interpreted with caution. Because the main hypothesis predicts that liberals (but not conservatives) will engage in a competence downshift, the omnibus interaction test does not provide a sensitive test of such a planned comparison relative to a crossover interaction (Rosnow \& Rosenthal, 1989). As such, the following analyses proceeded with planned comparisons to provide a focused test of the a priori prediction (e.g., Tybout \& Sternthal, 2001).

As illustrated in Figure 3, liberal participants ( $-1 S D$ from mean) engaged in a competence downshift, selecting words that would make them appear significantly less competent with a Black interaction partner than with a White one, $\beta=-.24,95 \% \mathrm{CI}=[-.46,-$ $.02], t(149)=-2.12, p=.036$. Conservative participants, in contrast, engaged in no such competence downshift, selecting words that would make them appear equally competent with a Black or White partner, $\beta=-.11,95 \% \mathrm{CI}=[-.33, .12], t(149)=-0.94, p=.350 .^{4}$

\footnotetext{
${ }^{4}$ There was no significant effect of Partner Race on self-reported conservatism across studies ( $p$ s $>$.209).
} 


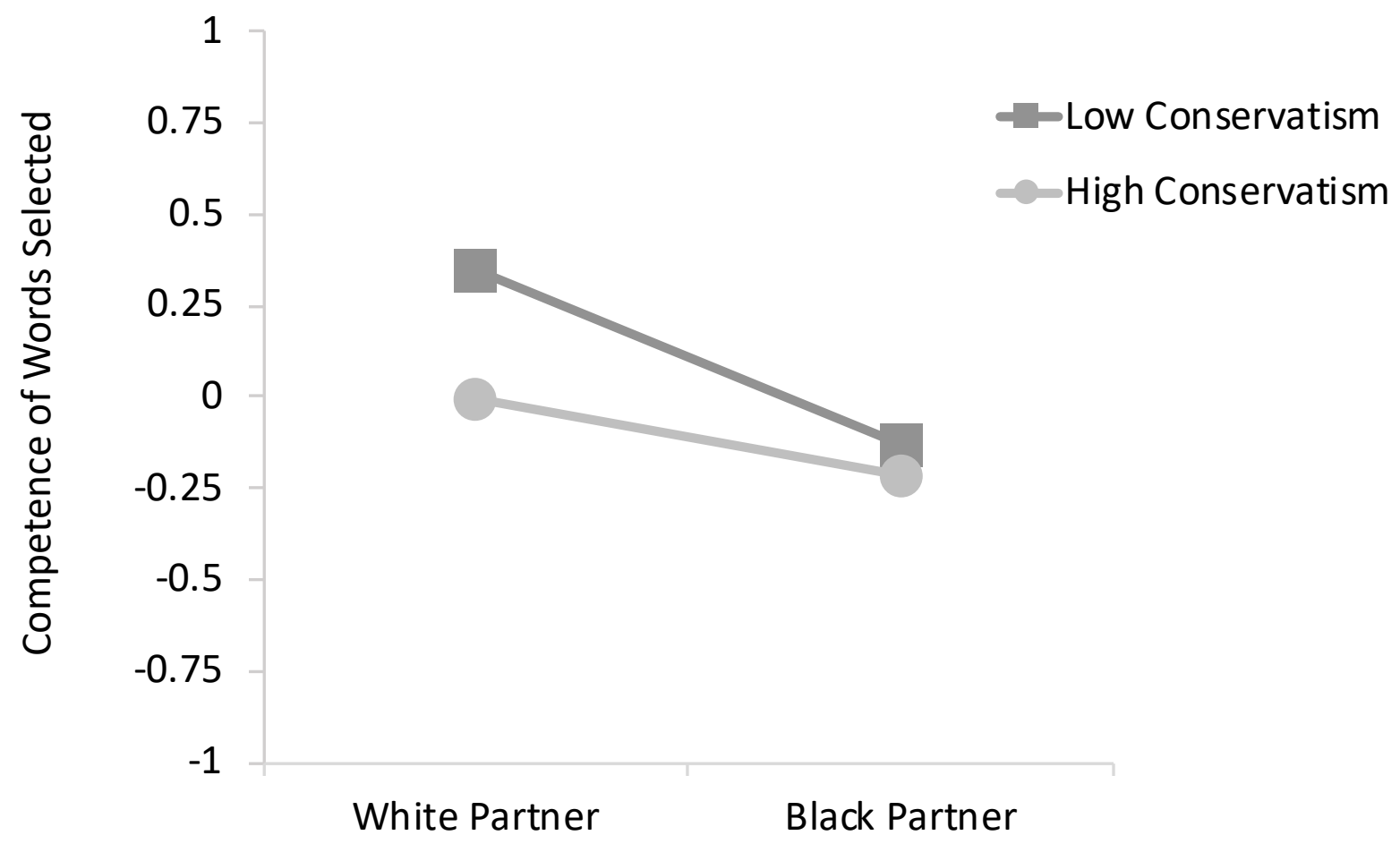

Figure 3. Competence of words (standardized residuals) selected as a function of partner race and self-reported conservatism (Study 2).

Warmth of word selections. No main effects or interactions reached significance ( $p s>$ $.081)$

Explicit interaction goals. Warmth and competence goals also were examined separately. Standardized residuals were examined.

Competence interaction goals. No main effects or interactions reached significance when predicting participants' competence-related interaction goals ( $p s>.429)$.

Warmth interaction goals. No main effects or interactions reached significance ( $p \mathrm{~s}>$ $.079)$.

\section{Discussion}

Studies 1 and 2 found that White liberals-Democratic presidential candidates in Study 1 and liberal students (-1 SD from mean) in Study 2-engaged in a competence downshift, presenting less competence to a Black interaction partner than to a White one. Both studies 
provide conservative tests of a liberal- (but not conservative-) enacted competence downshift as an affiliative self-presentational response. Study 1 tested the hypothesis by examining presidential campaign speeches. On the campaign trail, all candidates-Democrats and Republicans alike — are likely motivated to affiliate with minority audiences, potentially prompting even the more conservative speakers to adopt a competence downshift as an impression management strategy. Indeed, a significant main effect of audience race emergedoverall, politicians tended to present less competence to a mostly-minority audience than to a mostly-White one. Study 2 tested the hypothesis among students, who tend to be more liberal than the general population, thus having have a restricted range of political ideology. That is, even conservative students (those at $1 S D$ above the mean) are likely relatively liberal, more so than the general population. Again, a significant main effect of partner race was found-overall, students tended to present less competence (and more warmth) to a Black interaction partner than to a White one. However, focused tests of the primary hypothesis again revealed that, across studies, the competence downshift was significant for liberal (but not conservative) speakers.

\section{Study 3: A Book Review (mTurkers)}

Study 3 extends the prior findings in two ways. First, this study uses a more generalizable sample by recruiting users of Amazon's Mechanical Turk (mTurk). Researchers have suggested that drawing results from college-age convenience samples hinders the quality of inferences, arguing for replication with non-student samples before generalization (Druckman \& Kam, 2011; Peterson, 2001). The demographics of Mturk samples are more representative of the general population than are those of other convenience-based samples, such as university students (Berinsky et al., 2012; Buhrmester et al., 2011; Casler et al., 2013; Mason \& Suri, 2012; Paolacci et al., 2010).

Second, this study includes two individual difference variables that relate to a variety of socio-political attitudes and behaviors: Right Wing Authoritarianism (RWA; Altemeyer, 1981, 
THE COMPETENCE DOWNSHIFT BY WHITE LIBERALS

1988 ) and Social Dominance Orientation (SDO; Pratto, Sidanius, Stallworth, \& Malle, 1994).

White liberals (participants who are low in self-reported conservatism, SDO, or RWA) should present less competence to a Black interaction partner than to a White one, drawing on stereotypes that depict Blacks as lower in competence and status in an attempt to affiliate. These multiple indicators of conservatism were included as an exploratory step; we made no predictions as to which measure of conservatism would most predict liberals' competence downshift.

\section{Method}

Participants and design. Participants who self-identified as White $(N=431)$ were recruited online via Amazon.com's Mechanical Turk in exchange for a nominal fee. Participants were randomly assigned to an ingroup or outgroup partner condition in this two-cell betweensubjects design (Partner race: White, Black). The N aimed for roughly 100 Ps per combination of partner race and participant liberalism or conservatism.

Procedure. Participants read the same vignette featured in Study 2. Participants were again asked to imagine that they, as the new member of the book club, had to send a book review to the book club secretary, who was again given a stereotypically White or Black name. After selecting words to be included in their book review and reporting their explicit interaction goals, participants completed measures of values-based and hierarchy-based conservatism. Valuesbased conservatism was assessed using the 20-item RWA Scale as developed by Altemeyer (2006). Sample items include "Some of the best people in our country are those who are challenging our government, criticizing religion, and ignoring the "normal way things are meant to be done"” (reverse-scored) and "The 'old-fashioned ways' and 'old-fashioned values' still show the best way to live" $(\alpha=.97)$. Hierarchy-based conservatism was measured using the 16item SDO Scale developed by Pratto and colleagues (1994). Sample items include "We should do what we can to equalize conditions for different groups" (reverse-scored) and "Sometimes 
other groups must be kept in their place" $(\alpha=.96)$. Finally, participants provided demographic information, including self-reported conservatism $(1=$ extremely liberal, $7=$ extremely conservative).

\section{Results}

Preliminary analyses revealed no significant main effects or interactions as a function of participant gender. Therefore, all following analyses collapsed across participant gender. Warmth and competence ratings were slightly correlated $(r=.23, p<.001)$, as were all conservatism measures.

Self-presentation: Word selections. Warmth and competence were analyzed separately, the words being pretested for degrees of each trait.

Competence of word selections. As shown in Table 3, main effects of self-reported conservatism, hierarchy-based conservatism, and values-based conservatism emerged: overall, self-reported conservatives $(\beta=-.10,95 \% \mathrm{CI}=[-.20,-.01], t(425)=-2.12, p=.034)$, hierarchy-based conservatives $(\beta=-.14,95 \% \mathrm{CI}=[-.23,-.04], t(425)=-2.82, p=.005)$, and values-based conservatives $(\beta=-.17,95 \% \mathrm{CI}=[-.27,-.08], t(425)=-3.60, p<.001)$ presented less competence than their liberal counterparts. Main effects of self-reported conservatism and RWA were qualified by significant interactions with partner race (Conservatism $\times$ Partner Race: $\beta=.12,95 \% \mathrm{CI}=[.03, .22], t(425)=2.56, p=.011$; RWA $\times$ Partner Race: $\beta=.12,95 \% \mathrm{CI}=$ $[.03, .22], t(425)=2.60, p=.010)$. No other main effects or interactions reached significance $(p \mathrm{~s}$ $>$.339). 
Table 3

Summary of Regression Analyses for Interaction Partner Race, Self-Reported Conservatism Social Dominance Orientation (SDO), and RightWing Authoritarianism (RWA) Predicting Word Selection and Interaction Goals (Study 3)

\begin{tabular}{|c|c|c|c|c|c|c|c|c|}
\hline \multirow[b]{2}{*}{ Variables } & \multicolumn{4}{|c|}{ Competence of Word Selections } & \multicolumn{4}{|c|}{ Warmth of Word Selections } \\
\hline & $\beta$ & $t$ & $p$ & $95 \% \mathrm{CI}$ & $\beta$ & $t$ & $\bar{p}$ & $95 \% \mathrm{CI}$ \\
\hline \multicolumn{9}{|l|}{ Model 1: Conservatism } \\
\hline Conservatism & -.10 & $-2.12 *$ & .034 & {$[-.20,-.01]$} & .08 & 1.58 & .115 & {$[-.02, .17]$} \\
\hline Partner Race & -.02 & -0.50 & .619 & {$[-.12, .07]$} & .02 & 0.31 & .759 & {$[-.08, .11]$} \\
\hline Conservatism $\times$ Partner Race & .12 & $2.56 *$ & .011 & {$[.03, .22]$} & -.01 & -0.19 & .852 & {$[-.11, .09]$} \\
\hline Model $F$ & $3.39 *$ & & & & 0.89 & & & \\
\hline$R^{2}$ & .02 & & & & .00 & & & \\
\hline \multicolumn{9}{|l|}{ Model 2: SDO } \\
\hline SDO & -.14 & $-2.82 * *$ & .005 & {$[-.23,-.04]$} & .01 & 0.22 & .823 & {$[-.08, .11]$} \\
\hline Partner Race & -.03 & -0.56 & .574 & {$[-.12, .07]$} & .02 & 0.40 & .692 & {$[-.08, .11]$} \\
\hline SDO $\times$ Partner Race & .05 & 0.96 & .339 & {$[-.05, .14]$} & -.07 & -1.50 & .132 & {$[-.17, .02]$} \\
\hline Model $F$ & $2.95 *$ & & & & 0.80 & & & \\
\hline$R^{2}$ & .02 & & & & .01 & & & \\
\hline \multicolumn{9}{|l|}{ Model 3: RWA } \\
\hline RWA & -.17 & $-3.60 * * *$ & .000 & {$[-.27,-.08]$} & .11 & $2.27 *$ & .024 & {$[.01, .21]$} \\
\hline Partner Race & -.02 & -0.43 & .664 & {$[-.11, .07]$} & .01 & 0.28 & .783 & {$[-.08, .11]$} \\
\hline RWA $\times$ Partner Race & .12 & $2.60 *$ & .010 & {$[.03, .22]$} & -.06 & -1.18 & .240 & {$[-.15, .04]$} \\
\hline Model $F$ & $6.01 * *$ & & & & 2.04 & & & \\
\hline$R^{2}$ & .04 & & & & .01 & & & \\
\hline
\end{tabular}

Note. All dependent variables were residualized. All continuous variables were standardized. For all effects of Partner Race and interactions with Partner Race, White partner is coded as $-1 . \dagger p<.10 . * p<.05 . * * p<.01 . * * * p<.001$. 
Table 3 Continued

\begin{tabular}{|c|c|c|c|c|c|c|c|c|}
\hline \multirow{2}{*}{ Variables } & \multicolumn{4}{|c|}{ Competence Interaction Goals } & \multicolumn{4}{|c|}{ Warmth Interaction Goals } \\
\hline & $\beta$ & $t$ & $p$ & $95 \% \mathrm{CI}$ & $\beta$ & $t$ & $p$ & $95 \% \mathrm{CI}$ \\
\hline \multicolumn{9}{|l|}{ Model 1: Conservatism } \\
\hline Conservatism & -.05 & -0.92 & .356 & {$[-.14, .05]$} & .01 & 0.30 & .768 & {$[-.08, .11]$} \\
\hline Partner Race & .01 & 0.28 & .280 & {$[-.08, .11]$} & -.04 & -0.87 & .386 & {$[-.14, .05]$} \\
\hline Conservatism $\times$ Partner Race & .02 & 0.44 & .444 & {$[-.07, .12]$} & .01 & 0.19 & .853 & {$[-.09, .11]$} \\
\hline Model $F$ & 0.34 & & & & 0.29 & & & \\
\hline$R^{2}$ & .00 & & & & .00 & & & \\
\hline \multicolumn{9}{|l|}{ Model 2: SDO } \\
\hline SDO & .00 & 0.01 & .992 & {$[-.10, .10]$} & -.11 & $-2.34 *$ & .020 & {$[-.21,-.02]$} \\
\hline Partner Race & .01 & 0.22 & .825 & {$[-.08, .11]$} & -.04 & -0.79 & .428 & {$[-.13, .06]$} \\
\hline SDO $\times$ Partner Race & -.02 & -0.34 & .731 & {$[-.11, .08]$} & -.01 & -0.10 & .921 & {$[-.10, .09]$} \\
\hline Model $F$ & 0.06 & & & & $2.11 \dagger$ & & & \\
\hline$R^{2}$ & .00 & & & & .01 & & & \\
\hline \multicolumn{9}{|l|}{ Model 3: RWA } \\
\hline RWA & .00 & 0.07 & .992 & {$[-.09, .10]$} & .03 & 0.71 & .476 & {$[-.06, .13]$} \\
\hline Partner Race & .01 & 0.22 & .825 & {$[-.08, .11]$} & -.04 & -0.89 & .374 & {$[-.14, .05]$} \\
\hline RWA $\times$ Partner Race & .01 & 0.15 & .731 & {$[-.09, .10]$} & -.00 & -0.09 & .926 & {$[-.10, .09]$} \\
\hline Model $F$ & 0.06 & & & & 0.41 & & & \\
\hline$R^{2}$ & .00 & & & & .00 & & & \\
\hline
\end{tabular}

Note. All dependent variables were residualized. All continuous variables were standardized. For all effects of Partner Race and in teractions with Partner Race, White partner is coded as $-1 . \dagger p<.10 . * p<.05 . * * p<.01 . * * * p<.001$. 
In a focused test of the hypothesis, simple effect tests examined the effect of interaction partner race for liberal participants separately from conservative participants. Self-reported liberals and values-based liberals (i.e., Whites at $-1 S D$ below the means) demonstrated a competence downshift, selecting words that would make them appear significantly less competent with a Black partner than they did with a White partner (self-reported liberals: $\beta=-$ $.14,95 \% \mathrm{CI}=[-.28,-.01], t(425)=-2.18, p=.030$ (Figure 4); values-based liberals: $\beta=-.15$, $95 \% \mathrm{CI}=[-.28,-.01], t(425)=-2.16, p=.031)$.

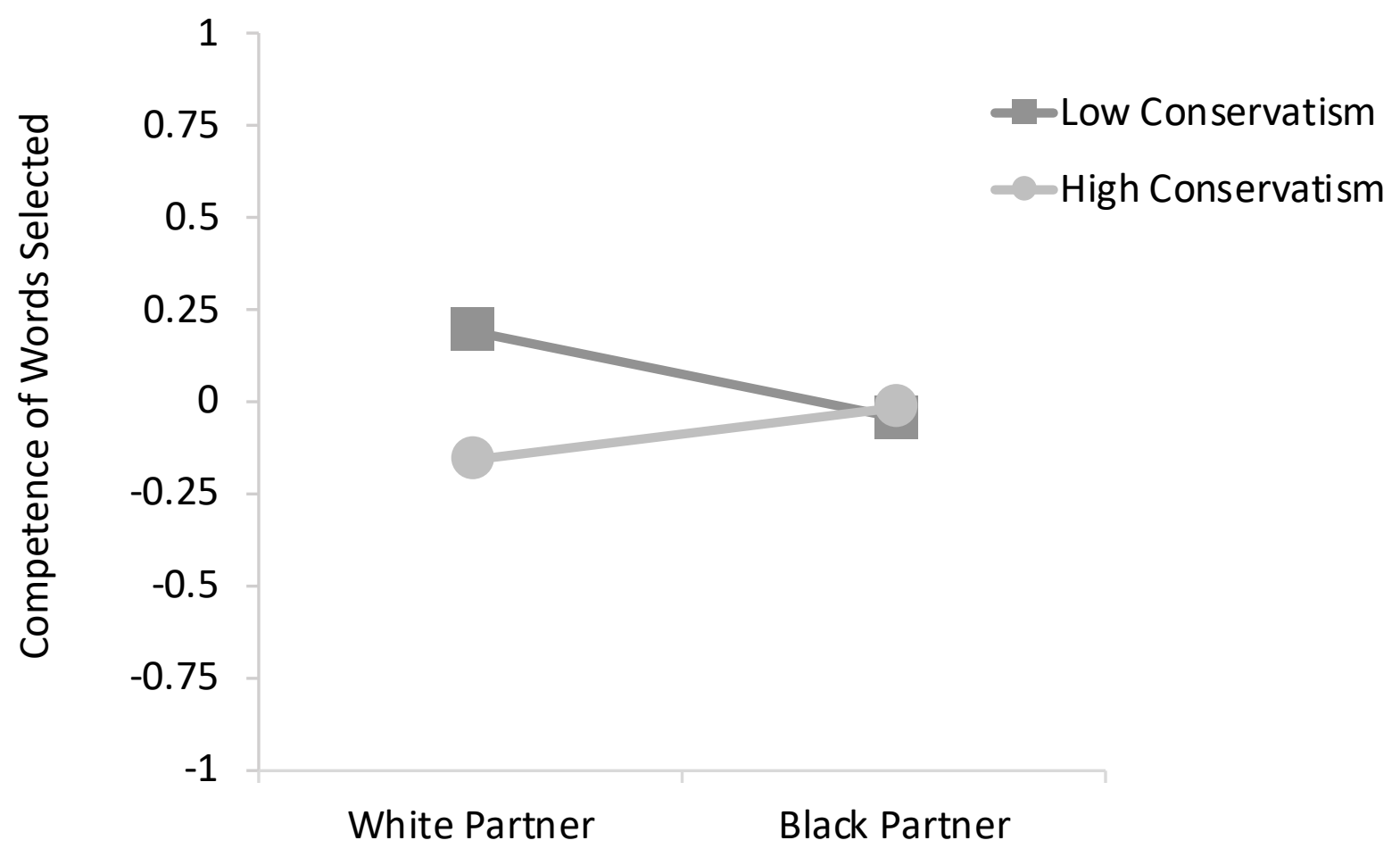

Figure 4. Competence of words (standardized residuals) selected as a function of partner race and self-reported conservatism (Study 3).

In contrast, self-reported conservatives and values-based conservatives (i.e., Whites at +1 $S D$ above the means) showed no such competence downshift (self-reported conservatives: $\beta=$ $.10,95 \% \mathrm{CI}=[-.04, .23], t(425)=1.45, p=.147$; values-based conservatives: $\beta=.10,95 \% \mathrm{CI}=$ 
$[-.03, .24], t(425)=1.53, p=.127$. Rather, these slopes were in the opposite direction. ${ }^{5,6}$

Warmth of word selections. A significant main effect of RWA emerged: values-based conservatives selected words that would make them appear warmer relative to their liberal counterparts, $\beta=.11,95 \% \mathrm{CI}=[.01, .21], t(425)=2.27, p=.024$. No other main effects or interactions reached significance $(p s>.134)$.

Explicit interaction goals. Warmth and competence goals also were examined separately.

Competence interaction goals. No main effects or interactions reached significance when predicting participants' competence-related interaction goals $(p s>.280)$.

Warmth interaction goals. A significant main effect of SDO emerged: Hierarchy-based conservatives reported a reduced desire to appear warm than did hierarchy-based liberals, $\beta=-$ $.11,95 \% \mathrm{CI}=[-.21,-.02], t(425)=-2.34, p=.020$. No other main effects of interactions reached significance $(p s>.374)$.

\section{Discussion}

Study 3 provides further support for the main hypothesis. White liberals, but not White conservatives, presented less competence to a Black interaction partner than they did to a White interaction partner. This effect held for self-reported liberals and for values-based liberals-those

\footnotetext{
${ }^{5}$ There was no significant effect of Partner Race on RWA or SDO scores across studies ( $p \mathrm{~s}$ > $.254)$.

${ }^{6}$ As an exploratory step, SDO scores were broken down into their two subdimensions of dominance (SDO-D) and anti-egalitarianism (SDO-E; Ho et al., 2012). As with all conservatism measures, the authors made no predictions as to whether SDO-D or SDO-E would be more likely to predict liberals' competence downshift. Results revealed that SDO-E, but not SDO-D ( $p=$ .954) non-significantly interacted with Partner Race to predict self-presentation of competence, $\beta$ $=.09,95 \% \mathrm{CI}=[-.01, .18], t(425)=1.82, p=.070$. Simple effects tests went on to interpret this interaction with caution, revealing that hierarchy-based (pro-egalitarian) liberals presented less competence to a Black partner than to a White one, $\beta=-.11,95 \% \mathrm{CI}=[-.25,-.02], t(425)=-$ $1.69, p=.091$. This effect was in the predicted direction, but not significant. Hierarchy-based (anti-egalitarian) conservatives showed no such competence downshift, $\beta=.06,95 \% \mathrm{CI}=[-.07$, .19 ], $t(425)=0.88, p=.038$. See Appendix C for full SDO-D and SDO-E results across studies.
} 
low in RWA, and less concerned with traditions and conventions - rather than hierarchy-based liberals - those low in SDO, and therefore less concerned with group-based dominance. Though, as noted in Footnote 6, participants low in SDO-E-i.e., those low in hierarchy-based dominance, especially anti-egalitarian sentiments — demonstrated a competence downshift that was in the predicted direction, but not significant.

Moreover, liberal Whites did not show differences in warmth presented to a White or Black interaction partner. This suggests that, while liberals may wish to affiliate with Blacks as much as they do with Whites, they may find themselves engaging in an ultimately-patronizing impression management strategy to do so, perhaps unwittingly dumbing themselves down in the process. The following study aims to replicate this effect and extend it with a more difficult test, involving a less competence-focused task.

\section{Study 4: An Introduction (Trait Selection)}

This study utilizes a modified self-presentation paradigm to further examine the competence downshift displayed by White liberals in Studies 1-3. In this study, White participants were asked to select self-descriptive personality traits to include in an introduction to a Black or White interaction partner. Thus, participants had the opportunity to present themselves as a person who is competent or warm. With this, Study 4 explores the use of the competence downshift in a context that could prioritize overall self-presentation of warmth (e.g., an introduction) rather than a context that could prioritize self-presentation of competence (e.g., a book review).

\section{Method}

Participants and design. Three-hundred and thirty-two Mechanical Turk users who selfidentified as White participated in exchange for a nominal fee. Participants were randomly assigned to either a White or a Black interaction partner in this two-cell between-subjects design. Although aiming for roughly 400 Ps who did not participate in Study 1, the current sampling had 
to terminate early because of academic deadlines.

Procedure. Participants first read a hypothetical scenario similar to that used in Studies 2 and 3. They were asked to imagine that they have recently joined a book club and must e-mail the book club secretary. For this study, the purpose of the e-mail was not to send an obligatory book review, but to send an introduction before the first meeting. The overall task, therefore, was less competence-related, inviting more movement along the dimension of warmth. The secretary was again given a stereotypically Black name or White name. After reading the scenario and completing the self-presentation measure, participants rated their explicit goals, completed the 20-item RWA and 16-item SDO scales, and answered demographic questions.

Participants selected 8 of 16 self-descriptive traits (e.g., ambitious, forgiving) to include in their introduction to a Black or White interaction partner. These traits were originally compiled by Rokeach (1973) to constitute instrumental values, which have been previously rated for morality- and competence-relatedness (Wojciszke, 1997; see Appendix D for ratings). ${ }^{7}$ These ratings were used to derive warmth and competence scores for each participant based on the traits selected for the introduction. The analysis weighted participants' trait selections by each trait's morality rating and competence rating. To create warmth and competence selfpresentation scores for all participants, the morality and competence ratings of the trait selections were averaged separately. As in the prior study, participants reported their competence- and warmth-related interaction goals by responding to the same seven items on a 100-point scale (competence-related goals: $\alpha=.61$; warmth-related goals: $\alpha=.71$ ).

Participants then completed Altemeyer's (2006) 20-item RWA Scale $(\alpha=.96)$, which

\footnotetext{
${ }^{7}$ As the introduction notes, several researchers have characterized morality as falling into one component of warmth, making it orthogonal to competence: Abele et al., 2016; Abele \& Wojciske, 2007; Fiske, Cuddy, \& Glick, 2007; Kervyn, Fiske, \& Yzerbyt, 2015; Leach, Ellemers, \& Barreto, 2007. Morality is just one component of warmth, including sincerity and trustworthiness, whereas friendliness and sociability are another correlated warmth component (Kervyn, Fiske, \& Yzerbyt, 2014).
} 
assessed values-based conservatism, and Pratto and colleagues' (1994) 16-item SDO Scale ( $\alpha=$ .95), which assessed hierarchy-based conservatism. Finally, participants provided demographic information, including self-reported conservatism $(1=$ extremely liberal, $7=$ extremely conservative).

\section{Results}

Preliminary analyses revealed no significant main effects or interactions as a function of participant gender, so subsequent analyses collapsed across gender. The study tested the prediction that Whites lower in conservatism - as measured via self-reported conservatism, SDO, or RWA — would show a competence downshift, selecting less competent traits with a Black partner than with a White partner. To test this hypothesis, multiple regression models analyzed the residualized competence and warmth scores of selected traits. As in Study 3, we ran three separate regression models for competence and for warmth - one model to test each measure of conservatism for competence and warmth. See Table 4 for the results of all regression analyses. 
Table 4

Summary of Regression Analyses for Interaction Partner Race, Self-Reported Conservatism, Social Dominance Orientation (SDO), and RightWing Authoritarianism (RWA) Predicting Trait Selections and Interaction Goals (Study 4)

\begin{tabular}{|c|c|c|c|c|c|c|c|c|}
\hline \multirow{2}{*}{ Variables } & \multicolumn{4}{|c|}{ Competence Trait Selections } & \multicolumn{4}{|c|}{ Warmth Trait Selections } \\
\hline & $\beta$ & $t$ & $p$ & $95 \% \mathrm{CI}$ & $\beta$ & $t$ & $p$ & $95 \% \mathrm{CI}$ \\
\hline \multicolumn{9}{|l|}{ Model 1: Conservatism } \\
\hline Conservatism & .02 & 0.40 & .693 & {$[-.09, .13]$} & .12 & $2.21 *$ & .028 & {$[.01, .23]$} \\
\hline Partner Race & -.04 & -0.71 & .479 & {$[-.15, .07]$} & -.09 & -1.60 & .110 & {$[-.19, .02]$} \\
\hline Conservatism $\times$ Partner Race & .08 & 1.52 & .127 & {$[-.02, .19]$} & .04 & 0.78 & .438 & {$[-.07, .15]$} \\
\hline Model $F$ & 0.99 & & & & $2.68 *$ & & & \\
\hline$R^{2}$ & .01 & & & & .02 & & & \\
\hline \multicolumn{9}{|l|}{ Model 2: SDO } \\
\hline SDO & .07 & 1.30 & .195 & {$[-.04, .18]$} & .11 & $2.00 *$ & .046 & {$[.00, .22]$} \\
\hline Partner Race & -.04 & -0.73 & .464 & {$[-.15, .07]$} & -.09 & $-1.65 \dagger$ & .099 & {$[-.20, .02]$} \\
\hline SDO $\times$ Partner Race & .02 & 0.32 & .753 & {$[-.09, .13]$} & .04 & 0.69 & .493 & {$[-.07, .15]$} \\
\hline Model $F$ & 0.75 & & & & $2.32 \dagger$ & & & \\
\hline$R^{2}$ & .01 & & & & .02 & & & \\
\hline \multicolumn{9}{|l|}{ Model 3: RWA } \\
\hline RWA & -.05 & -0.82 & .413 & {$[-.15, .06]$} & .12 & $2.27 *$ & .024 & {$[.02, .23]$} \\
\hline Partner Race & -.04 & -0.75 & .456 & {$[-.15, .07]$} & -.08 & -1.55 & .127 & {$[-.19, .02]$} \\
\hline RWA $\times$ Partner Race & .08 & 1.46 & .145 & {$[-.03, .19]$} & -.03 & -0.61 & .543 & {$[-.14, .07]$} \\
\hline Model $F$ & 1.19 & & & & $2.83 *$ & & & \\
\hline$R^{2}$ & .01 & & & & .03 & & & \\
\hline
\end{tabular}

Note. All dependent variables were residualized. All continuous variables were standardized. For all effects of Partner Race and interactions with Partner Race, White partner is coded as $-1 . \dagger p<.10 . * p<.05 . * * p<.01 . * * * p<.001$. 
Table 4 Continued

\begin{tabular}{|c|c|c|c|c|c|c|c|c|}
\hline \multirow{2}{*}{ Variables } & \multicolumn{4}{|c|}{ Competence Interaction Goals } & \multicolumn{4}{|c|}{ Warmth Interaction Goals } \\
\hline & $\beta$ & $t$ & $p$ & $95 \% \mathrm{CI}$ & $\beta$ & $t$ & $p$ & $95 \% \mathrm{CI}$ \\
\hline \multicolumn{9}{|l|}{ Model 1: Conservatism } \\
\hline Conservatism & .04 & 0.69 & .489 & {$[-.07, .15]$} & .04 & 0.65 & .513 & {$[-.07, .14]$} \\
\hline Partner Race & .01 & 0.19 & .853 & {$[-.10, .11]$} & .03 & 0.55 & .579 & {$[-.08, .14]$} \\
\hline Conservatism $\times$ Partner Race & .04 & 0.80 & .798 & {$[-.06, .15]$} & -.03 & -0.50 & .623 & {$[-.14, .08]$} \\
\hline Model $F$ & 0.99 & & & & $2.68 *$ & & & \\
\hline$R^{2}$ & .01 & & & & .02 & & & \\
\hline \multicolumn{9}{|l|}{ Model 2: SDO } \\
\hline $\mathrm{SDO}$ & -.02 & -0.42 & .672 & {$[-.13, .09]$} & -.07 & -1.35 & .178 & {$[-.18, .03]$} \\
\hline Partner Race & .01 & 0.18 & .852 & {$[-.10, .12]$} & .03 & 0.57 & .568 & {$[-.08, .14]$} \\
\hline SDO $\times$ Partner Race & -.06 & -1.13 & .259 & {$[-.17, .05]$} & -.01 & -0.21 & .838 & {$[-.12, .10]$} \\
\hline Model $F$ & 0.48 & & & & 0.71 & & & \\
\hline$R^{2}$ & .00 & & & & .01 & & & \\
\hline \multicolumn{9}{|l|}{ Model 3: RWA } \\
\hline RWA & -.05 & -0.83 & .406 & {$[-.16, .06]$} & .05 & 1.00 & .323 & {$[-.05, .16]$} \\
\hline Partner Race & .01 & 0.14 & .885 & {$[-.10, .12]$} & .03 & 0.59 & .555 & {$[-.08, .14]$} \\
\hline RWA $\times$ Partner Race & .00 & 0.07 & .942 & {$[-.10, .11]$} & -.04 & -0.78 & .434 & {$[-.15, .07]$} \\
\hline Model $F$ & 0.25 & & & & 0.69 & & & \\
\hline$R^{2}$ & .00 & & & & .01 & & & \\
\hline
\end{tabular}

Note. All dependent variables were residualized. All continuous variables were standardized. For all effects of Partner Race and interactions with Partner Race, White partner is coded as $-1 . \dagger p<.10 . * p<.05 . * * p<.01 . * * * p<.001$. 
Self-presentation: Trait selections. Competence and warmth were analyzed separately.

Competence of trait selections. No main effects or interactions reached significance ( $p \mathrm{~s}>$ $.127)$.

As the two-way interactions did not reach significance, simple effects must be interpreted with caution. However, the authors moved forward with planned comparisons because, as noted, the omnibus interaction is not well-suited to capture the predicted difference between liberals' and conservatives' outgroup (vs. ingroup) self-presentation (Rosnow \& Rosenthal, 1989). In a focused test of the hypothesis, simple slopes analyses examined the effect of interaction partner race for liberal participants separately from conservative participants. Results provided suggestive evidence of liberals' competence downshift. Self-reported liberals and values-based liberals $(-1 S D)$ selected less competent traits with a Black partner than they did with a White one (self-reported liberals: $\beta=-.12,95 \% \mathrm{CI}=[-.28, .03], t(328)=-1.59, p=.115$ (Figure 5); values-based liberals: $\beta=-.12,95 \% \mathrm{CI}=[-.27, .03], t(328)=-1.56, p=.119$. While these effects were in the predicted direction, they did not reach significance. As in prior studies, conservatives showed no such competence downshift (self-reported conservatives: $\beta=.05,95 \%$ $\mathrm{CI}=[-.11, .20], t(328)=0.58, p=.562$; values-based conservatives: $\beta=.04,95 \% \mathrm{CI}=[-.11$, $.19], t(328)=0.51, p=.612$. Rather, these slopes were in the positive direction. 


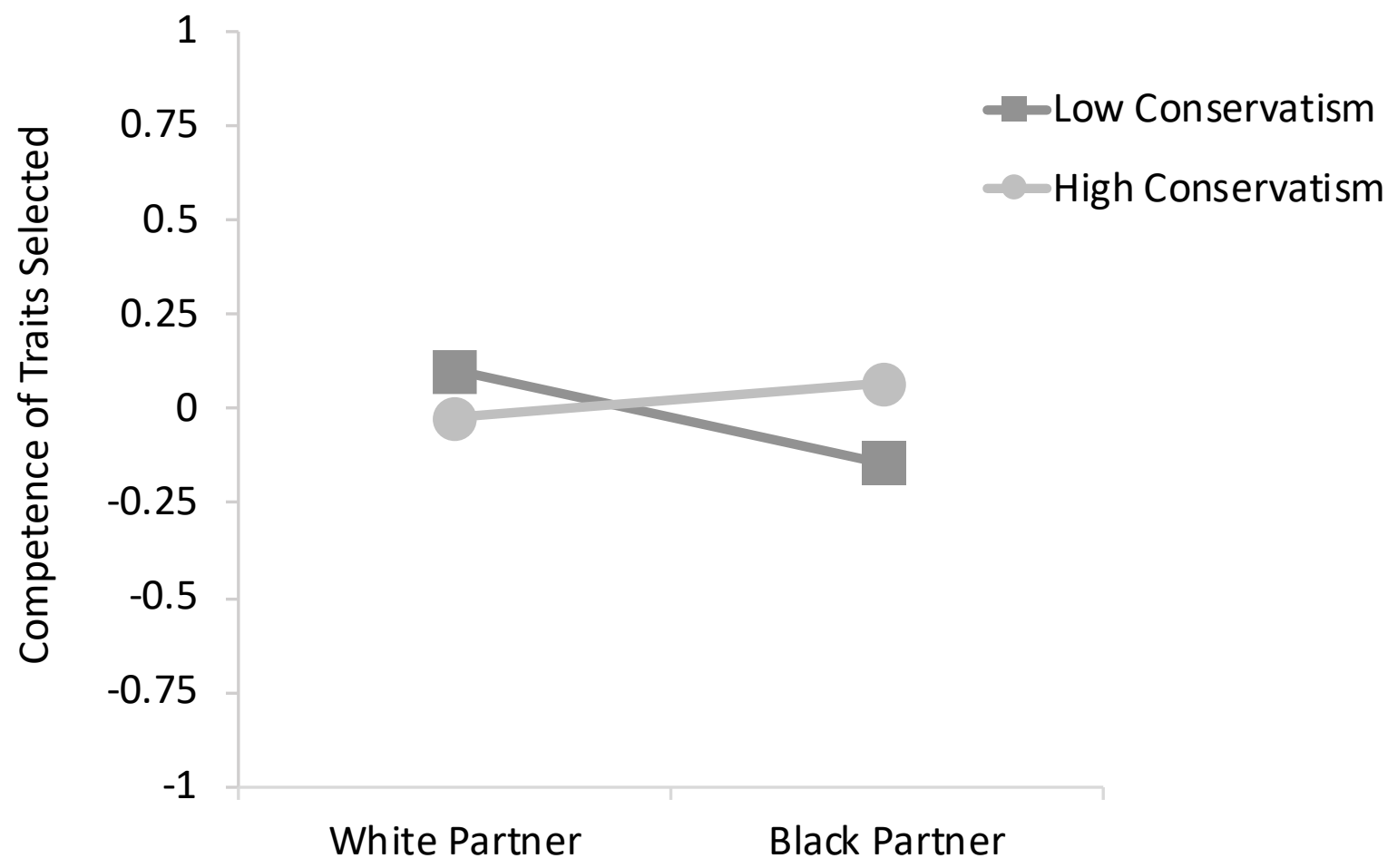

Figure 5. Competence of traits (standardized residuals) selected as a function of partner race and self-reported conservatism (Study 4).

Warmth of trait selections. Significant main effects of self-reported, hierarchy-based, and values-based conservatism emerged: overall, conservatives selected warmer traits to describe themselves than did their liberal counterparts (self-reported conservatism: $\beta=.12,95 \% \mathrm{CI}=$ $[.01, .23], t(328)=2.21, p=.028$; hierarchy-based conservatism: $\beta=.11,95 \% \mathrm{CI}=[.00, .22]$ $t(328)=2.00, p=.046$; values-based conservatism: $\beta=.12,95 \% \mathrm{CI}=[.02, .23], t(328)=2.27, p$ $=.024)$. No other main effects or interactions reached significance ( $p s>.099)$.

Explicit interaction goals. Again, the two dimensions were analyzed separately.

Competence interaction goals. No main effects or interactions reached significance when predicting participants' competence-related interaction goals $(p s>.259)$.

Warmth interaction goals. No main effects or interactions reached significance when predicting participants' warmth-related interaction goals ( $p \mathrm{~s}>.178)$.

\section{Discussion}


This study provides suggestive evidence of a competence downshift displayed by White liberals (but not conservatives) when responding to a Black (versus White) interaction partner. However, the competence downshift displayed by self-reported liberals and values-based liberals was weaker than that found in prior studies. The critical simple slope, while in the predicted direction, did not reach significance. The non-significant effect in this study may be a function of the less competence-focused task (i.e., an introduction) and measure of self-presentation (i.e., selecting self-descriptive traits for an introduction). Importantly, the pattern of results replicates that found in prior studies. Furthermore, the competence downshift effect is robust when subjected to internal meta-analysis, which includes the effects found across all studies (including this one; full results to follow).

Thus far, results across four studies suggest that the liberals' competence downshift is a subtle, but consistent effect. The pattern and direction of results replicate, and the critical simple effect is significant when subjected to internal meta-analysis. However, prior studies face a number of limitations. While Study 4's paradigm constituted a tougher test of the competence downshift, the scenario still involved a book club (competence-related), and a hypothetical vignette only goes so far to approximate real-world scenarios of self-presentation. Furthermore, Studies 2-4 all measured self-presentation through word selection, rather than open-ended responses, a more natural form of verbal behavior. Finally, these studies signaled interactionpartner race exclusively through the use of a stereotypically Black or White name. Although the field has used this method extensively, stereotypical names may confound race and status. Often the stereotypically Black names imply lower status than do the stereotypically White names used in intergroup research (Fryer \& Levitt, 2004). Race alone likely elicits these effects without status cues (Fiske, Dupree, Nicolas, \& Swencionis, 2016). However, the use of visual images would improve this issue.

In light of these limitations, the next study tackled the task of replicating the competence 
downshift with an open-ended self-presentation task, in which participants would present themselves to a presumably real White or Black interaction partner, as signaled by avatars with brown or white skin and less-stereotypical first names.

\section{Study 5: An Introduction (Open-Ended)}

\section{Method}

Participants and design. Seven hundred and forty-three Mechanical Turk users who self-identified as White participated in exchange for a nominal fee. Any participants who failed the manipulation check by incorrectly identifying the avatar of their online partner $(n=33)$ or who failed either of two attention-check items $(n=58)$ were excluded. The resulting sample size was 652. As in prior experiments, this study featured a two-cell between-subjects design (Partner race: White, Black). The larger $\mathrm{N}$ was designed to increase power to detect smaller effects that might not have emerged in the prior experiments, as well as enhancing detection of the competence downshift in the new paradigm.

Procedure. Participants signed up to complete a study that ostensibly examined online communication. During this study, participants created an online profile as a means of introducing themselves to another participant (i.e., their online partner). This online partner was described as another Mechanical Turk user who previously completed a similar study, which required this person to complete his or her own online profile. Participants were told that this partner would view participants' own online profile in a follow-up study. (In reality, there were no online partners.) Before completing their own online profile, participants reviewed information about their partner.

Participants viewed the first name of the partner, as well as an avatar that their partner ostensibly chose to represent himself or herself. Participants randomly assigned to the White interaction-partner condition viewed an avatar with light skin, blond hair, and blue eyes, which was given a stereotypically White name (Emily or Jake), both pretested to fall on the midpoint of 
stereotypicality $(1=$ Not at all, $7=$ Very $m u c h)$. Participants randomly paired with a Black partner viewed an avatar with medium-brown skin, brown hair, and brown eyes, paired with a stereotypically Black name (Tamara or Darnell), both pretested to fall on the midpoint of stereotypicality. Online partners were gender-matched to participants.

After viewing details about their online partner, participants provided their own first name and selected an avatar to represent themselves. To ensure that partner race remained salient, the following screen included the first name and avatar that they selected ("You provided the following name and avatar"), followed by the first name and avatar of their interaction partner ("Your online partner provided the following name and avatar").

Participants then introduced themselves to their partner. This constituted the primary selfpresentation measure for this study. The following page, entitled "Introduce yourself!" included an essay box in which participants could write their introduction. This screen included the following instructions, adapted from a similar paradigm used by Scopelliti, Loewenstein, and Vosgerau (2015):

We would like for you to introduce yourself to your online partner by creating a personal profile. Please use full sentences and write as much as you can to make sure that your online partner gets a good sense of who you are. (Include at least 5 sentences). For example, you could write about your favorite sports or hobbies, your work or education, your social life, your appearance or personality, your family.

Participants then completed their online profile, describing their personality by responding to a series of traits. As in Study 4, this measure determined whether liberals described themselves as less competent with a Black partner than they did with a White one. Unlike Study 4, participants were not forced to choose particular traits—rather, they responded to each one. On the following page, entitled "Describe yourself!", participants responded to a total of 16 traits (honest, capable, ambitious, logical, responsible, courageous, helpful, 
intellectual, forgiving, polite, cheerful, obedient, imaginative, self-controlled, independent, loving), rating on a 1-7 Likert Scale how much each trait applied to them. All traits were previously rated on morality- and competence-relatedness (Wojciszke, 1997).

Participants then provided their interaction goals. On the following page, entitled "Your profile is complete!", participants rated how they wished to appear, responding to eight items (kind, likeable, open, competent, intelligent, fair, friendly, honest) on a 1-7 Likert scale. As in prior studies, this measure determined whether liberals expressed the explicit desire to appear less competent (or more warm) to a Black interaction partner than to a White one. Competencerelated items (competent, intelligent) were averaged to index participants' competence interaction goals $(\alpha=.95)$. Warmth-related items (kind, likeable, open, fair, friendly, honest) were averaged to index participants' warmth interaction goals $(\alpha=.88)$.

Participants then provided their anticipated partner evaluations, making their best guess as to how they would appear to their interaction partner. This measure assessed the perceived efficacy of a competence downshift - that is, whether participants who engaged in such a response expected to be seen as less competent (or more warm) by a Black partner than by a White one. On the following page, entitled "What will your partner think of you?", participants responded to eight items on a 1-7 Likert scale. Competence-related items (competent, intelligent) were averaged to index how much participants expected to be seen as competent $(\alpha=.95)$. Warmth-related items (kind, likeable, open, fair, friendly, honest) were averaged to index how much participants expected to be seen as warm $(\alpha=.89)$.

A manipulation check followed; participants were asked to identify the avatar that their online partner selected. Participants who did not correctly identify the avatar of their Black or White partner failed this manipulation check and were excluded. Finally, values- and hierarchybased conservatism were again assessed using the 20-item RWA Scale (Altemeyer, 2006) $(\alpha=$ .96) and the 16-item SDO Scale (Pratto et al., 1994) $(\alpha=.96)$, respectively. For this study, two 
attention-check items were embedded within the RWA and SDO questionnaires: sentences such as "When counting up, the number nine comes after the number ten." Participants ended the survey by providing demographic information, including self-reported conservatism $(1=$ extremely liberal, 7 = extremely conservative).

\section{Results}

Content of introductions. As in Study 1, self-presentation was assessed using competence and warmth dictionaries. The competence dictionary was derived from published lists of agentic words and from LIWC's power dictionary (e.g., assertive, competitive; Gaucher, Friesen, \& Kay, 2011; Pennebaker, Booth, Boyd, \& Francis, 2015; Rudman \& Killianski, 2000). The warmth dictionary was derived from published lists of communal words and from LIWC's affiliation dictionary (e.g., supportive, compassionate; Gaucher, Friesen, \& Kay, 2011;

Pennebaker, Booth, Boyd, \& Francis, 2015; Rudman \& Killianski, 2000). Using LIWC, each speech was given a competence self-presentation score and a warmth self-presentation score based on the percentage of times words from the corresponding dictionaries occurred within each introduction.

Analyses treated competence and warmth scores separately. As in prior studies, each selfpresentation score was residualized off the other; these standardized residuals were analyzed. Three multiple regression models tested the effects of interaction partner race and conservatism on all dependent variables: one model for each conservatism measure. See Table 5 for results of all regression analyses. ${ }^{8}$

As in prior studies, preliminary analyses tested whether participant gender interacted with partner race or any conservatism measure to predict the dependent variables of interest.

\footnotetext{
${ }^{8}$ As an exploratory measure, readability of text was also examined by analysis of introductions' Flesch Reading Ease Score (Flesch, 1948) and Flesch-Kincaid Grade Level (Kincaid, Fishburne, Rogers, \& Chissom, 1975). See Appendix E in the Supplemental Materials for these results.
} 
Preliminary analyses revealed no moderating effect of participant gender, so subsequent analyses collapsed across gender. 
Table 5

Summary of Regression Analyses for Interaction Partner Race, Self-Reported Conservatism, Social Dominance Orientation (SDO), and Right-Wing Authoritarianism (RWA) Predicting Trait Ratings, Content of Introductions, Interaction Goals, and Perceived Partner Responses (Study 5)

\begin{tabular}{|c|c|c|c|c|c|c|c|c|}
\hline \multirow{2}{*}{ Variables } & \multicolumn{4}{|c|}{ Competence Word Usage } & \multicolumn{4}{|c|}{ W armth Word Usage } \\
\hline & $\beta$ & $t$ & $p$ & $95 \% \mathrm{CI}$ & $\beta$ & $t$ & $p$ & $95 \% \mathrm{CI}$ \\
\hline \multicolumn{9}{|l|}{ Model 1: Conservatism } \\
\hline Conservatism & .02 & 0.55 & .580 & {$[-.06, .10]$} & .06 & 1.59 & .112 & {$[-.02, .14]$} \\
\hline Partner Race & -.06 & -1.55 & .121 & {$[-.14, .02]$} & .02 & 0.53 & .597 & {$[-.06, .10]$} \\
\hline Conservatism $\times$ Partner Race & .00 & -0.01 & .989 & {$[-.08, .08]$} & -.00 & -0.10 & .921 & {$[-.08, .07]$} \\
\hline Model $F$ & 0.93 & & & & 0.92 & & & \\
\hline$R^{2}$ & .00 & & & & .00 & & & \\
\hline \multicolumn{9}{|l|}{ Model 2: SDO } \\
\hline $\mathrm{SDO}$ & .00 & -0.02 & .984 & {$[-.08, .08]$} & .01 & 0.23 & .818 & {$[-.07, .09]$} \\
\hline Partner Race & -.06 & -1.58 & .112 & {$[-.14, .02]$} & .02 & 0.46 & .644 & {$[-.06, .10]$} \\
\hline SDO $\times$ Partner Race & .07 & $1.73 \dagger$ & .084 & {$[-.01, .14]$} & -.01 & -0.27 & .785 & {$[-.09, .07]$} \\
\hline Model $F$ & 1.83 & & & & 0.11 & & & \\
\hline$R^{2}$ & .01 & & & & .00 & & & \\
\hline \multicolumn{9}{|l|}{ Model 3: RWA } \\
\hline RWA & .04 & 0.95 & .345 & {$[-.04, .11]$} & .08 & $2.00 *$ & .046 & {$[.00, .15]$} \\
\hline Partner Race & -.06 & -1.56 & .120 & {$[-.14, .02]$} & .02 & 0.51 & .610 & {$[-.06, .10]$} \\
\hline RWA $\times$ Partner Race & -.03 & -0.80 & .427 & {$[-.11, .05]$} & -.05 & -1.28 & .199 & {$[-.13, .03]$} \\
\hline Model $F$ & 1.35 & & & & 1.99 & & & \\
\hline$R^{2}$ & .01 & & & & .01 & & & \\
\hline
\end{tabular}

Note. All dependent variables were residualized. All continuous variables were standardized. For all effects of Partner Race and interactions with

Partner Race, White partner is coded as $-1 . \dagger p<.10 . * p<.05 . * * p<.01 . * * * p<.001$. 
Table 5 Continued

\begin{tabular}{|c|c|c|c|c|c|c|c|c|}
\hline \multirow{2}{*}{ Variables } & \multicolumn{4}{|c|}{ Competence of Trait Ratings } & \multicolumn{4}{|c|}{ W armth of Trait Ratings } \\
\hline & $\beta$ & $t$ & $\bar{p}$ & $95 \% \mathrm{CI}$ & $\bar{\beta}$ & $t$ & $\bar{p}$ & $95 \% \mathrm{CI}$ \\
\hline \multicolumn{9}{|l|}{ Model 1: Conservatism } \\
\hline Conservatism & .04 & 1.08 & .279 & {$[-.03, .12]$} & -.02 & -0.39 & .697 & {$[-.09, .06]$} \\
\hline Partner Race & .04 & 1.06 & 290 & {$[-.04, .12]$} & -.04 & -1.10 & .272 & {$[-.12, .03]$} \\
\hline Conservatism $\times$ Partner Race & .02 & 0.54 & .536 & {$[-.06, .10]$} & -.04 & -1.13 & .259 & {$[-.12, .03]$} \\
\hline Model $F$ & 0.83 & & & & 0.87 & & & \\
\hline$R^{2}$ & .00 & & & & .00 & & & \\
\hline \multicolumn{9}{|l|}{ Model 2: SDO } \\
\hline SDO & .12 & $3.14 * *$ & .002 & {$[.05, .20]$} & -.13 & $-3.36 * * *$ & .001 & {$[-.21,-.05]$} \\
\hline Partner Race & .04 & 1.06 & .288 & {$[-.03, .12]$} & -.04 & -1.14 & .256 & {$[-.12, .03]$} \\
\hline SDO $\times$ Partner Race & .10 & $2.45^{*}$ & 014 & {$[.02, .17]$} & -.10 & $-2.52 *$ & .012 & {$[-.17,-.02]$} \\
\hline Model $F$ & $5.66 * * *$ & & & & $6.30 * * *$ & & & \\
\hline$R^{2}$ & .03 & & & & .03 & & & \\
\hline \multicolumn{9}{|l|}{ Model 3: RWA } \\
\hline RWA & -.05 & -1.25 & .213 & {$[-.13, .03]$} & .08 & $2.12 *$ & .034 & {$[.01, .16]$} \\
\hline Partner Race & .04 & 0.98 & .326 & {$[-.04, .12]$} & -.04 & -1.03 & .301 & {$[-.12, .04]$} \\
\hline RWA $\times$ Partner Race & .01 & 0.31 & .759 & {$[-.07, .09]$} & -.03 & -0.88 & .382 & {$[-.11, .04]$} \\
\hline Model $F$ & 0.90 & & & & $2.18 \dagger$ & & & \\
\hline$R^{2}$ & .00 & & & & .01 & & & \\
\hline
\end{tabular}

Note. All dependent variables were residualized. All continuous variables were standardized. For all effects of Partner Race and in teractions with Partner Race, White partner is coded as $-1 . \dagger p<.10 . * p<.05 . * * p<.01 . * * * p<.001$. 
Table 5 Continued

\begin{tabular}{|c|c|c|c|c|c|c|c|c|}
\hline \multirow{2}{*}{ Variables } & \multicolumn{4}{|c|}{ Competence Interaction Goals } & \multicolumn{4}{|c|}{ Warmth Interaction Goals } \\
\hline & $\beta$ & $t$ & $p$ & $95 \% \mathrm{CI}$ & $\beta$ & $t$ & $p$ & $95 \% \mathrm{CI}$ \\
\hline \multicolumn{9}{|l|}{ Model 1: Conservatism } \\
\hline Conservatism & -.01 & -0.30 & .764 & {$[-.09, .07]$} & .05 & 1.35 & .176 & {$[-.02, .13]$} \\
\hline Partner Race & -.05 & -1.19 & .237 & {$[-.12, .03]$} & .04 & 0.99 & .323 & {$[-.04, .12]$} \\
\hline Conservatism $\times$ Partner Race & .10 & $2.60 *$ & .010 & {$[.03, .18]$} & -.09 & $-2.39 *$ & .017 & {$[-.18,-.02]$} \\
\hline Model $F$ & $2.75^{*}$ & & & & 0.92 & & & \\
\hline$R^{2}$ & .01 & & & & .00 & & & \\
\hline \multicolumn{9}{|l|}{ Model 2: SDO } \\
\hline SDO & .15 & 3.85 & .000 & {$[.07, .22]$} & -.14 & $-3.65 * * *$ & .000 & {$[-.22,-.07]$} \\
\hline Partner Race & -.04 & -1.14 & .255 & {$[-.12, .03]$} & .03 & 0.90 & .371 & {$[-.04, .11]$} \\
\hline SDO $\times$ Partner Race & .08 & $2.02 *$ & .044 & {$[.00, .15]$} & -.05 & -1.16 & .246 & {$[-.12, .03]$} \\
\hline Model $F$ & $6.78 * * *$ & & & & $5.21 * *$ & & & \\
\hline$R^{2}$ & .03 & & & & .02 & & & \\
\hline \multicolumn{9}{|l|}{ Model 3: RWA } \\
\hline RWA & -.01 & -0.21 & .831 & {$[-.09, .07]$} & .11 & $2.93 * *$ & .004 & {$[.04, .19]$} \\
\hline Partner Race & -.05 & -1.18 & .239 & {$[-.12, .03]$} & .04 & 1.01 & .314 & {$[-.04, .12]$} \\
\hline RWA $\times$ Partner Race & .09 & $2.24 *$ & .026 & {$[.01, .16]$} & -.07 & $-1.69 \dagger$ & .092 & {$[-.14, .01]$} \\
\hline Model $F$ & $2.15 \dagger$ & & & & $4.18 * *$ & & & \\
\hline$R^{2}$ & .01 & & & & .02 & & & \\
\hline
\end{tabular}

Note. All dependent variables were residualized. All continuous variables were standardized. For all effects of Partner Race and interactions with Partner Race, White partner is coded as $-1 . \dagger p<.10 . * p<.05 . * * p<.01 . * * * p<.001$. 
Table 5 Continued

\begin{tabular}{|c|c|c|c|c|c|c|c|c|}
\hline \multirow{2}{*}{ Variables } & \multicolumn{4}{|c|}{ Anticipated Partner Evaluation: Competence } & \multicolumn{4}{|c|}{ Anticipated Partner Evaluation: Warmth } \\
\hline & $\beta$ & $t$ & $p$ & $95 \% \mathrm{CI}$ & $\beta$ & $t$ & $p$ & $95 \% \mathrm{CI}$ \\
\hline \multicolumn{9}{|l|}{ Model 1: Conservatism } \\
\hline Conservatism & -.07 & $-1.67+$ & .095 & {$[-.14, .01]$} & .12 & $3.17 * *$ & .002 & {$[.05, .20]$} \\
\hline Partner Race & .00 & 0.09 & .927 & {$[-.07, .08]$} & -.01 & -0.22 & .825 & {$[-.09, .07]$} \\
\hline Conservatism $\times$ Partner Race & .07 & $1.67 \dagger$ & .095 & {$[-.01, .14]$} & -.09 & $-2.34 *$ & .020 & {$[-.17,-.01]$} \\
\hline Model $F$ & 1.89 & & & & $5.25 * *$ & & & \\
\hline$R^{2}$ & .01 & & & & .02 & & & \\
\hline \multicolumn{9}{|l|}{ Model 2: SDO } \\
\hline SDO & .03 & 0.83 & .417 & {$[-.05, .11]$} & -.10 & -2.43 & .015 & {$[-.17,-.02]$} \\
\hline Partner Race & .01 & 0.17 & .863 & {$[-.07, .08]$} & -.02 & -0.38 & .702 & {$[-.09, .06]$} \\
\hline SDO $\times$ Partner Race & .09 & $2.31 *$ & .021 & {$[.01, .17]$} & -.05 & -1.30 & .193 & {$[-.13, .03]$} \\
\hline Model $F$ & 2.01 & & & & $2.59 \dagger$ & & & \\
\hline$R^{2}$ & .01 & & & & .01 & & & \\
\hline \multicolumn{9}{|l|}{ Model 3: RWA } \\
\hline RWA & -.09 & -2.38 & .017 & {$[-.17,-.02]$} & .17 & $4.42 * * *$ & .000 & {$[.10, .25]$} \\
\hline Partner Race & .00 & 0.11 & .917 & {$[-.07, .08]$} & -.01 & -0.25 & .803 & {$[-.09, .07]$} \\
\hline RWA $\times$ Partner Race & .05 & 1.24 & .214 & {$[-.03, .13]$} & -.03 & -0.77 & .442 & {$[-.11, .05]$} \\
\hline Model $F$ & $2.47 \dagger$ & & & & $6.63 * * *$ & & & \\
\hline$R^{2}$ & .01 & & & & .03 & & & \\
\hline
\end{tabular}

Note. All dependent variables were residualized. All continuous variables were standardized. For all effects of Partner Race and interactions with Partner Race, White partner is coded as $-1 . \dagger p<.10 . * p<.05 . * * p<.01 . * * * p<.001$. 
Table 5 Continued

\begin{tabular}{|c|c|c|c|c|c|c|c|c|}
\hline \multirow{2}{*}{ Variables } & \multicolumn{4}{|c|}{ Perceived Interaction Goals: Competence } & \multicolumn{4}{|c|}{ Perceived Interaction Goals: W armth } \\
\hline & $\beta$ & $t$ & $p$ & $95 \% \mathrm{CI}$ & $\beta$ & $t$ & $p$ & $95 \% \mathrm{CI}$ \\
\hline \multicolumn{9}{|l|}{ Model 1: Conservatism } \\
\hline Conservatism & -.03 & -0.67 & .501 & {$[-.10, .05]$} & .07 & $1.69 \dagger$ & .092 & {$[-.01, .14]$} \\
\hline Partner Race & .04 & 1.02 & .307 & {$[-.04, .12]$} & -.02 & -0.47 & .641 & {$[-.10, .06]$} \\
\hline Conservatism $\times$ Partner Race & .00 & 0.02 & .983 & {$[-.08, .08]$} & -.01 & -0.18 & .855 & {$[-.08, .07]$} \\
\hline Model $F$ & 0.52 & & & & 1.06 & & & \\
\hline$R^{2}$ & .00 & & & & .00 & & & \\
\hline \multicolumn{9}{|l|}{ Model 2: SDO } \\
\hline SDO & .03 & 0.71 & .477 & {$[-.05, .11]$} & -.02 & -0.60 & .546 & {$[-.10, .05]$} \\
\hline Partner Race & .04 & 1.06 & .288 & {$[-.04, .12]$} & -.02 & -0.55 & .584 & {$[-.10, .06]$} \\
\hline SDO $\times$ Partner Race & .06 & 1.59 & .113 & {$[-.02, .14]$} & -.06 & -1.52 & .130 & {$[-.14, .02]$} \\
\hline Model $F$ & 1.38 & & & & $2.59 \dagger$ & & & \\
\hline$R^{2}$ & .01 & & & & .01 & & & \\
\hline \multicolumn{9}{|l|}{ Model 3: RWA } \\
\hline RWA & -.04 & -0.90 & .368 & {$[-.11, .04]$} & .08 & $2.14 *$ & .030 & {$[.01, .16]$} \\
\hline Partner Race & .04 & 1.03 & .303 & {$[-.04, .12]$} & -.02 & -0.49 & .625 & {$[-.10, .06]$} \\
\hline RWA $\times$ Partner Race & .04 & 0.94 & .346 & {$[-.04, .11]$} & -.01 & -0.12 & .907 & {$[-.08, .07]$} \\
\hline Model $F$ & 0.95 & & & & 1.63 & & & \\
\hline$R^{2}$ & .00 & & & & .01 & & & \\
\hline
\end{tabular}

Note. All dependent variables were residualized. All continuous variables were standardized. For all effects of Partner Race and interactions with Partner Race, White partner is coded as $-1 . \dagger p<.10 . * p<.05 . * * p<.01 . * * * p<.001$. 
Participants' overall word usage across conditions. Participants were asked to write at least 5 sentences for their introduction to their online partner. On average, participants wrote 66.89 words $(S D=30.09)$, with an average of 11.92 words per sentence $(S D=5.50)$. Turning to the dependent variables, percentages of competence $(M=1.85, S D=1.97$, skew $=1.30$, kurtosis $=1.81)$ and warmth $(\mathrm{M}=4.92, \mathrm{SD}=3.47$, skew $=1.38$, kurtosis $=4.11)$ words used fell within the acceptable limits of $+/-2$ on skewness (Gravetter \& Wallnau, 2014; Trochim \& Donnelly, 2006).

Competence word usage. The SDO $\times$ Partner Race interaction emerged, but did not reach significance, $\beta=.07,95 \% \mathrm{CI}=[-.01, .14], t(648)=1.73, p=.084$. No other main effects or interactions reached significance $(p s>.121)$.

As in prior studies, simple effects tests were conducted with caution, providing a focused test of the a priori prediction: a liberal- (but not conservative-) enacted competence downshift. As shown in Figure 6, hierarchy-based liberals showed a competence downshift, utilizing significantly fewer competence-related words with a Black partner than they did with a White one, $\beta=-.13,95 \% \mathrm{CI}=[-.24,-.02], t(648)=-2.34, p=.019$. Hierarchy-based conservatives showed no such competence downshift, utilizing an equal number of competence-related words with a Black or White partner, $\beta=.01,95 \% \mathrm{CI}=[-.10, .11], t(648)=0.11, p=.914$. 


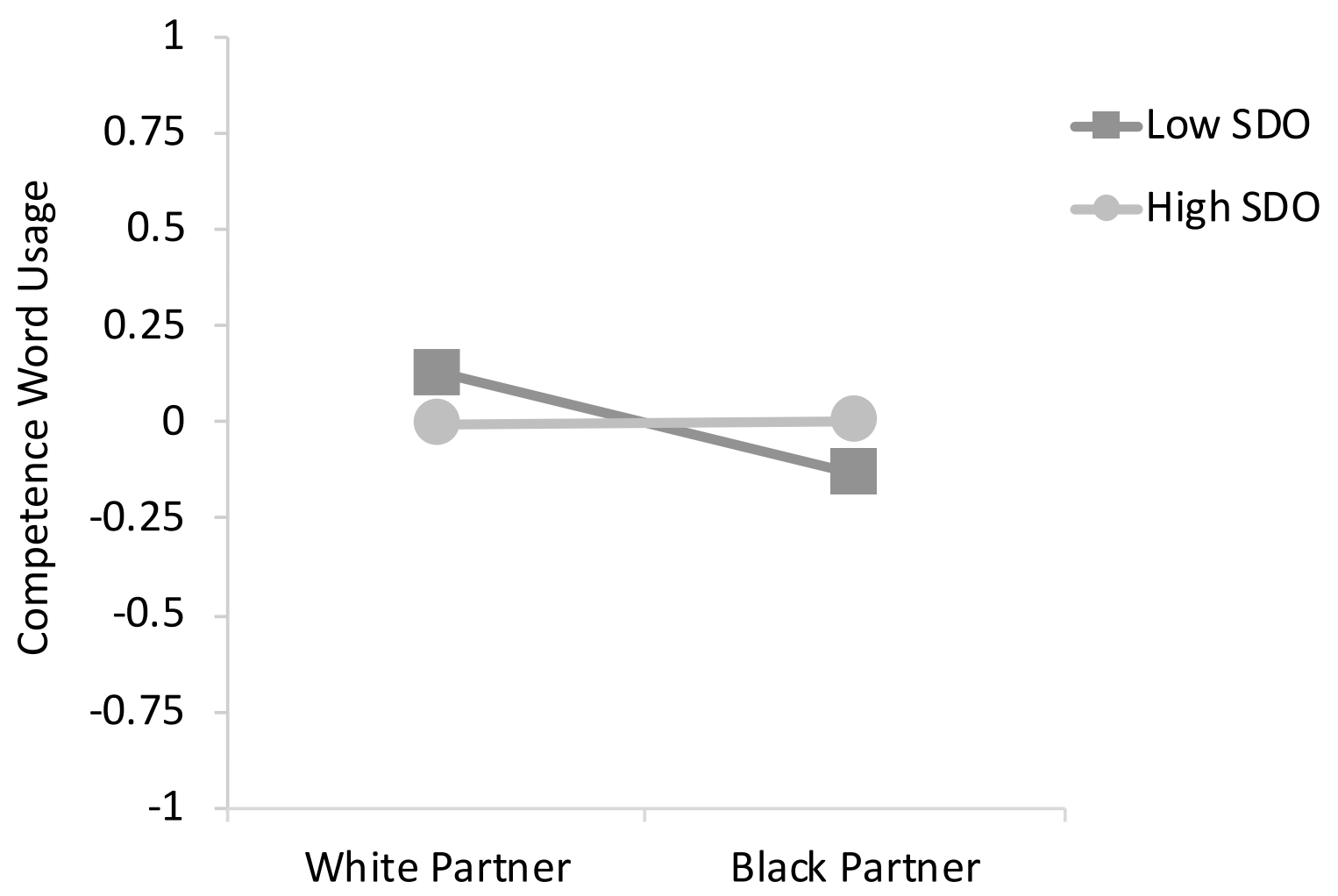

Figure 6. Percentage of competence-related words (standardized residuals) used in participants' introductions as a function of partner race and SDO (Study 5). SDO = Social Dominance Orientation.

Warmth word usage. A significant main effect of values-based conservatism emerged: values-based conservatives used more warmth-related words than did their liberal counterparts, $\beta$ $=.08,95 \% \mathrm{CI}=[.00, .15], t(648)=2.00, p=.046$. No other main effects or interactions reached significance $(p s>.112)$.

Self-descriptive traits ratings. To create a competence and warmth self-description score for each trait, participants' selections were weighted by each traits' competence- and warmth-relatedness score. Take, for example, a participant who selected 5 for "logical". Because that trait's competence-relatedness rating is 7.94 , her competence self-description score for that trait would be $39.70(5 \times 7.94)$. Because that traits' morality-relatedness rating is 3.24 , her warmth self-description score for that trait would be $16.20(5 \times 3.24)$. Competence and warmth 
self-description scores for each trait were then averaged, creating overall warmth $(\alpha=.82)$ and competence $(\alpha=.81)$ self-description scores. Competence and warmth self-description scores were residualized off the opposing measure and standardized for all analyses. Preliminary analyses revealed no moderating effect of participant gender, so subsequent analyses collapsed across gender.

Competence of traits ratings. A main effect of SDO emerged: Hierarchy-based conservatives described themselves as significantly more competent than did hierarchy-based liberals, $\beta=.12,95 \% \mathrm{CI}=[.05, .20], t(648)=3.14, p=.002$. This main effect was qualified by a significant interaction with partner race, $\beta=.10,95 \% \mathrm{CI}=[.02, .17], t(648)=2.45, p=.014$. No other main effects or interactions reached significance $(p s>.213)$.

Unexpectedly, hierarchy-based conservatives showed a competence upshift, describing themselves as significantly more competent with a Black partner than they did with a White one, $\beta=.14,95 \% \mathrm{CI}=[.03, .24], t(648)=2.49, p=.031$. In contrast, hierarchy-based liberals showed no such upshift, described themselves as equally competent with a Black or White partner, $\beta=-$ $.05,95 \% \mathrm{CI}=[-.16, .05], t(648)=0.98, p=.325$. Indeed, the direction of the (non-significant) slope is suggestive of a competence downshift, rather than an upshift.

Warmth of traits ratings. Significant main effects of RWA and SDO emerged: valuesbased conservatives described themselves as warmer than did their liberal counterparts, $\beta=.08$, $95 \%=[.01, .16], t(648)=2.12, p=.034$. In contrast, hierarchy-based conservatives described themselves as colder than did their liberal counterparts, $\beta=-.13,95 \%=[-.21,-.05], t(648)=-$ $3.36, p=.001$. The SDO main effect was qualified by a significant interaction with partner race, $\beta=-.12,95 \%=[-.17,-.02], t(648)=-2.52, p=.012$. No other main effects or interactions reached significance $(p s>.259)$.

Hierarchy-based conservatives showed a warmth downshift, describing themselves as significantly colder with a Black partner than they did with a White one, $\beta=-.14,95 \% \mathrm{CI}=[-$ 
$.25,-.03], t(648)=-2.58, p=.010$. In contrast, hierarchy-based liberals showed no such downshift, describing themselves as equally warm with a Black or White partner, $\beta=.05,95 \%$ $\mathrm{CI}=[-.05, .16], t(648)=0.98, p=.329$. Indeed, the direction of the (non-significant) slope is suggestive of a warmth upshift, rather than a downshift.

Explicit interaction goals. Competence and warmth interaction goals were residualized off the opposing measure and standardized for all analyses. Preliminary analyses revealed no moderating effect of participant gender, so subsequent analyses collapsed across gender.

Competence interaction goals. A main effect of hierarchy-based conservatism emerged to predict participants' competence-related interaction goals. Overall, hierarchy-based conservatives reported an increased desire to appear competent relative to their liberal counterparts, $\beta=.15,95 \% \mathrm{CI}=[.07, .22], t(648)=3.85, p<.001$. All three interactions reached significance: Conservatism $\times$ Partner Race $(\beta=.10,95 \% \mathrm{CI}=[.02, .18], t(648)=2.60, p=.010)$, SDO $\times$ Partner Race $(\beta=.08,95 \% \mathrm{CI}=[.00, .15], t(648)=2.02, p=.044)$, and RWA $\times$ Partner Race $(\beta=.09,95 \% \mathrm{CI}=[.01, .16], t(648)=2.24, p=.026)$. No other main effects reached significance $(p s>.237)$.

In a focused test of the hypothesis, simple effects tests examined the effect of partner race on liberals' competence-related interaction goals. Results revealed that, across conservatism measures, liberals reported a significantly reduced desire to appear competent with a Black interaction partner than with a White one (self-reported liberals: $\beta=-.15,95 \% \mathrm{CI}=[-.26,-.04]$, $t(648)=-2.68, p=.008 ;$ hierarchy-based liberals: $\beta=-.12,95 \% \mathrm{CI}=[-.22,-.01], t(648)=-$ 2.23, $p=.026$; values-based liberals: $\beta=-.13,95 \% \mathrm{CI}=[-.24,-.03], t(648)=-2.42, p=.016)$. Conservatives, in contrast, reported no difference in competence-related interaction goals as a function of partner race (self-reported conservatives: $\beta=.06,95 \% \mathrm{CI}=[-.05, .16], t(648)=1.00$, $p=.317$; hierarchy-based conservatives: $\beta=.03,95 \% \mathrm{CI}=[-.07, .14], t(648)=0.62, p=.533$; 
values-based conservatives: $\beta=.04,95 \% \mathrm{CI}=[-.07, .15], t(648)=0.75, p=.454)$.

Warmth interaction goals. Significant main effects of SDO and RWA emerged.

Hierarchy-based conservatives reported a reduced desire to appear warm relative to their liberal counterparts $(\beta=-.14,95 \% \mathrm{CI}=[-.22,-.07], t(648)=-3.65, p<.001)$. In contrast, values-based conservatives reported an increased desire to appear warm relative to their liberal counterparts $(\beta$ $=.11,95 \% \mathrm{CI}=[.04, .19], t(648)=2.93, p=.004)$. A significant Self-Reported Conservatism $\times$ Partner Race interaction also emerged, $\beta=-.09,95 \% \mathrm{CI}=[-.18,-.02], t(648)=-2.39, p=.017$. No other interactions or main effects reached significance $(p s>.092)$.

Simple effects tests revealed that self-reported liberals reported having more warmthrelated goals with a Black interaction partner than White one, $\beta=.13,95 \% \mathrm{CI}=[.02, .24], t(648)$ $=2.39, p=.017$. Their conservative counterparts, in contrast, reported no difference in warmthrelated interaction goals as a function of partner race, $\beta=-.05,95 \% \mathrm{CI}=[-.16, .05], t(648)=-$ $0.99, p=.324$

Anticipated partner evaluations. Anticipated partner evaluation scores related to competence and warmth were residualized off the opposing measure and standardized for all analyses. Preliminary analyses revealed no moderating effect of participant gender, so subsequent analyses collapsed across gender.

Anticipated partner evaluation: Competence. A significant main effect of values-based conservatism emerged to predict participants' anticipated partner evaluations related to competence. Overall, values-based conservatives anticipated that any interaction partner would find them less competent relative to their liberal counterparts, $\beta=-.09,95 \% \mathrm{CI}=[-.17,-.02]$, $t(648)=-2.38, p=.017$. One significant interaction also emerged: SDO $\times$ Partner Race, $\beta=.09$, $95 \% \mathrm{CI}=[.01, .17], t(648)=-2.31, p=.021$. No other main effects or interactions reached significance ( $p$ s >.214). 
Simple effects tests revealed that hierarchy-based liberals anticipated appearing less competent with a Black partner than with a White one, $\beta=-.08,95 \% \mathrm{CI}=[-.19, .03], t(648)=-$ $1.51, p=.135$. This simple slope, while in the predicted direction, did not reach significance. This pattern flipped for hierarchy-based conservatives, who anticipated appearing (nonsignificantly) more competent with a Black partner than with a White one, $\beta=.10,95 \% \mathrm{CI}=[-$ $.01, .21], t(648)=1.75, p=.080)$.

Anticipated partner evaluation: Warmth. Significant main effects of self-reported conservatism and values-based conservatism emerged to predict participants' anticipated partner evaluations related to warmth. Overall, self-reported conservatives and values-based conservatives anticipated appearing significantly warmer than did their liberal counterparts (selfreported conservatism: $\beta=.12,95 \% \mathrm{CI}=[.05, .20], t(648)=3.17, p=.002$; values-based conservatism: $\beta=.17,95 \% \mathrm{CI}=[.10, .25], t(648)=4.42, p<.001)$. In contrast, hierarchy-based conservatives anticipated appearing significantly colder than did their liberal counterparts, $\beta=-$ $.10,95 \% \mathrm{CI}=[-.17,-.02], t(648)=-2.43, p=.015$. The main effect of self-reported conservatism was qualified by a significant interaction with partner race, $\beta=-.09,95 \% \mathrm{CI}=[-$ $.17,-.01], t(648)=-2.34, p=.020$. No other main effects or interactions reached significance $(p s>.193)$.

Simple effects tests revealed no significant results, but the directions were as predicted: self-reported liberals anticipated appearing (non-significantly) warmer with a Black interaction partner than with a White one, $\beta=.08,95 \% \mathrm{CI}=[-.03, .19], t(648)=1.50, p=.135$. Their conservative counterparts, in contrast, anticipated appearing (non-significantly) colder with a Black interaction partner than with a White one, $\beta=-.10,95 \% \mathrm{CI}=[-.21, .01], t(648)=-1.81, p$ $=.071$.

Perceptions of speakers' interaction goals from language. As a final measure, a separate sample of mTurk raters was recruited to judge the writers' impression management 
strategies - specifically, raters judged how warm or competent the writers wished to appear, based solely on the language provided in the brief written introductions. As shown in prior work, people converge on their judgments of others - forming similar impressions based on brief, thinslices of behavior (Ambady, Bernieri, \& Richeson, 2000). Recently, Voigt and colleagues (2017) found that participants perceived differences in respect presented to Black (versus White) community members by police officers from reviewing brief, transcribed utterances.

To test whether raters' judgments of writers' interaction goals differed based on the conservatism of the writer or the race of the recipient, 674 raters (338 women) were recruited using Amazon's Mechanical Turk to review the 652 introductions. Introductions were grouped into batches of 10; raters were randomly assigned to one batch. The order in which introductions were presented was randomized. Each introduction was reviewed by $8-11$ raters. Raters reported how warm or competent they thought the author was trying to appear, rating warmth and competence interaction goals each on a 6 -point scale $(1=$ Not at all, $6=$ Extremely $)$. Accuracy was incentivized by informing participants that authors rated their actual interaction goals after writing their introductions - raters were told that those who were $100 \%$ accurate on all writers' interaction goals would receive a bonus.

The warmth and competence scores that judges gave for each introduction were averaged across raters, creating perceived warmth and competence impression management scores for each introduction. These standardized residual scores were then submitted to two simultaneous linear regression models, determining whether conservatism of the writer (self-reported, hierarchy-based, values-based) or race of the recipient (i.e., the interaction partner) predicted judgments of the writers' interaction goals.

Perceived interaction goals: Competence. The interaction between hierarchy-based conservatism and partner race was in the predicted direction, but did not reach significance, $\beta=$ $.06,95 \% \mathrm{CI}=[-.02, .14], t(648)=1.59, p=.113$. No main effects or interactions reached 
significance when predicting judges' predictions of participants' competence-related goals ( $p s$ > $.303)$.

With caution, simple effects tests examined the effect of partner race separately for hierarchy-based liberals and conservatives. Judges perceived that hierarchy-based conservatives wished to appear (more competent with a Black interaction partner than with a White one, $\beta=$ $.10,95 \% \mathrm{CI}=[-.01, .21], t(648)=1.87, p=.062$. This simple slope was in the predicted direction, but did not reach significance. In contrast, judges perceived that hierarchy-based liberals wished to appear similarly competent with a Black partner as they did with a White one, $\beta=-.02,95 \% \mathrm{CI}=[-.13, .08], t(646)=-0.37, p=.712$.

Perceived interaction goals: Warmth. A significant main effect of values-based conservatism emerged: overall, judges perceived that values-based conservatives wished to appear more warm than did their liberal counterparts, $\beta=.08,95 \% \mathrm{CI}=[.01, .16], t(648)=2.14$, $p=.030$. No other main effects or interactions reached significance $(p s>.092)$.

\section{Discussion}

In Study 5, Whites low in hierarchy-based conservatism - that is, those who outwardly reject a hierarchical society, failing to prioritize dominance over other social groupsdemonstrated a competence downshift: using fewer competence-related words with a Black interaction partner than a White one. Furthermore, across all conservatism measures in Study 5-self-reported conservatism, hierarchy-based conservatism, and values-based conservatismliberals reported having the goal to appear significantly less competent with a Black interaction partner than with a White one. Conservatives reported no such difference in their interaction goals based on partner race. This finding represents a departure from previous studies, in which liberals' competence self-presentation varied based on partner race more so than their selfreported interaction goals. In prior studies, the interaction was hypothetical, and the interaction partner's race was signaled with stereotypically White or Black names. In this study, the 
interaction was presumed real, and the interaction partner's race was signaled visually with

White or Black avatars, also given stereotypically White or Black names. In this more realistic, dynamic interracial setting, perhaps interaction goals are more accessible to high-status group members, such that they are more able to explicitly report group-based differences in their interaction goals.

The results of this study also represent a departure from those of prior studies, in that the competence downshift was most strongly found among hierarchy-based liberals. Again, this study provided a more realistic, dynamic interracial setting. In such a setting, perhaps group dominance lies at the forefront of high-status group members' attention, thus most strongly impacting their impression management strategies. If so, then it is possible that hierarchy-based liberals are particularly motivated to affiliate with racial minorities, prompting the competence downshift. As noted, liberals across conservatism measures report having less competencerelated interaction goals with a Black versus White interaction partner. Furthermore, hierarchybased liberals low in anti-egalitarian sentiments-i.e., SDO-E_-also displayed a (nonsignificant) competence downshift in Study 3 (see Footnote 6). Further exploration of the conditions under which various indicators of conservatism predict interracial impression management is necessary. These results, however, provide evidence that the competence downshift can also be found among hierarchy-based liberals in more realistic and dynamic interracial settings.

\section{Internal meta-analysis}

The strength of the critical simple effect - the competence downshift displayed by liberals_-varied across studies. The simple effect reached significance $(p<.05)$ on a least one conservatism variable in Studies 1, 2, 3, and 5, while, in Study 4, the simple effect did not reach significance (self-reported liberals: $p=.115$; value-based liberals: $p=.119$; see Table 6 for all effect sizes). In Study 1, self-identified Democrats demonstrated a competence downshift; in 
Studies 2-4, self-reported liberals showed the effect. Values-based liberals showed the effect in

Studies 3 and 4, and hierarchy-based liberals showed the effect in Study 5. Because all studies tested the same research question and employed a similar design, an internal or "mini" metaanalysis is an appropriate test of the overall effects sizes (Goh, Hall, \& Rosenthal, 2016). 
Table 6

Effects sizes for used in meta-analyses testing liberals'versus conservatives' self-presentation of competence across studies

\begin{tabular}{|c|c|c|c|c|c|c|c|}
\hline \multirow[b]{2}{*}{ Measure and study } & \multirow[b]{2}{*}{$n$} & \multicolumn{3}{|c|}{ Liberals } & \multicolumn{3}{|c|}{ Conservatives } \\
\hline & & $\beta$ & $p$ & $95 \% \mathrm{CI}$ & $\beta$ & $p$ & $95 \% \mathrm{CI}$ \\
\hline \multicolumn{8}{|l|}{ Conservatism } \\
\hline Study 1 & 74 & $-.32 *$ & .020 & {$[-.58,-.05]$} & -.27 & .110 & {$[-.61, .06]$} \\
\hline Study 2 & 153 & $-.24 *$ & .036 & {$[-.46,-.02]$} & -.11 & .350 & {$[-.33, .12]$} \\
\hline Study 3 & 431 & $-.15 *$ & .030 & {$[-.28,-.01]$} & .10 & .147 & {$[-.04,23]$} \\
\hline Study 4 & 332 & -.12 & .115 & {$[-.28, .03]$} & .05 & .562 & {$[-.11, .20]$} \\
\hline Study 5 & 652 & -.06 & .277 & {$[-.17, .05]$} & -.06 & .269 & {$[-.17, .05]$} \\
\hline Study S1 & 589 & .04 & .473 & {$[-.12, .20]$} & $.19 *$ & .020 & {$[.03, .36]$} \\
\hline \multicolumn{7}{|l|}{ SDO } & {$[-.11, .15]$} \\
\hline Study 4 & 332 & -.06 & .460 & {$[-.21, .10]$} & -.02 & .769 & {$[-.18, .13]$} \\
\hline Study 5 & 652 & $-.13 *$ & .020 & {$[-.24,-.02]$} & .01 & .914 & {$[-.10, .11]$} \\
\hline \multicolumn{8}{|l|}{ RWA } \\
\hline Study 3 & 431 & $-.15 *$ & .031 & {$[-.28,-.01]$} & .10 & .127 & {$[-.03, .24]$} \\
\hline Study 4 & 332 & -.12 & .119 & {$[-.27, .03]$} & .04 & .612 & {$[-.11, .19]$} \\
\hline Study 5 & 652 & -.03 & .591 & {$[-.14, .08]$} & $-.09 \dagger$ & .097 & {$[-.20, .02]$} \\
\hline Study S1 & 589 & .03 & .731 & {$[-.13, .19]$} & $.20 *$ & .018 & {$[.03, .37]$} \\
\hline
\end{tabular}

Note. All dependent variables were residualized. All continuous variables were standardized. For all effects of Partner Race and interactions with Partner Race, White partner is coded as $-1 . \dagger p<.10 . * p<.05 . * * p<.01 . * * * p<.001$. 
The mini meta-analysis tested the overall effect sizes of the competence downshift found among liberals in all studies, across all conservatism measures ${ }^{9}$. All meta-analytic calculations were performed using the SPSS macro MeanES developed by Wilson (2005). In a more conservative test of the overall effect sizes, random-effects models were chosen. While fixedeffects models assume one true population effect size, random-effects models assume variability within and across studies, producing results that are more generalizable (Field \& Gillett, 2010; Hedges \& Vevea, 1998). It has been recommended that random-effects models be assumed in most social sciences, because real-world data are likely to have heterogeneous population effect sizes (Field, 2003; Field \& Gillett, 2010). Furthermore, Study 1 was included only in metaanalyses of self-reported liberals and conservatives, as registering as Democrat or Republican likely most closely approximates a self-reported conservatism measure. Finally, while Study 5 included multiple dependent variables, results from the primary self-presentation measure (i.e., frequency of competence-related word usage) were utilized for the meta-analyses including this study. This decision was made for congruence with Study 1 - which also utilized this measureand because this particular measure (i.e., word usage in open-ended speech) most closely approximates real world speech, which affords the opportunity to engage in impression management responses through self-presentation.

As shown in Table 7, when meta-analyzed across studies, the competence downshift reached significance for self-reported liberal and low-SDO Whites. Across the six studies that included a measure of self-reported conservatism, self-reported liberals presented significantly

${ }^{9}$ To address a potential file-drawer problem, this meta-analysis included the results of an additional study that attempted to test mediation by manipulating a proposed mediator. White and Black interaction partner control conditions were analyzed for self-reported conservatism and RWA (SDO was not included in this study); these results are included in the internal metaanalysis. Details of this study can be found in Appendix F of the Supplemental Material. 
less competence to a Black interaction partner than they did to a White one, Mean ES =-.11, $95 \% \mathrm{CI}=[-.20,-.03], z=-2.69, p=.007$. Meta-analysis of the effects found among hierarchyand value-based liberals across the three and four studies, respectively, that included these measures revealed similar results. Hierarchy-based liberals presented significantly less competence to a Black versus White interaction partner across studies, Mean $E S=-.10,95 \% \mathrm{CI}$ $=[-.17,-.02], z=-2.54, p=.011$. For values-based liberals, this simple effect, while in the predicted direction, did not reach significance, Mean $E S=-.07,95 \% \mathrm{CI}=[-.14, .01], z=-1.79$, $p=.073)$. Meta-analysis of the other simple effects - that is, the effect of interaction partner race for conservatives - reveal no such downshift effect. Overall, White self-reported (Mean $E S=.01$, $95 \% \mathrm{CI}=[-.09, .11], z=-0.65, p=.795)$, hierarchy-based $($ Mean $E S=.00,95 \% \mathrm{CI}=[-.07$, $.08], z=0.09, p=.932)$, and values-based (Mean $E S=.05,95 \% \mathrm{CI}=[-.07, .18], z=0.84, p$ $=.399$ ) conservatives presented equal competence to a Black interaction partner as they did to a White one. 
Table 7

Internalmeta-analyses: Results

\begin{tabular}{|c|c|c|c|c|c|c|c|}
\hline \multirow[b]{2}{*}{ Conservatism measure } & \multirow[b]{2}{*}{$n^{\mathrm{a}}$} & \multicolumn{3}{|c|}{ Liberals } & \multicolumn{3}{|c|}{ Conservatives } \\
\hline & & $\beta$ & $\bar{p}$ & $95 \% \mathrm{CI}$ & $\beta$ & $\bar{p}$ & $95 \% \mathrm{CI}$ \\
\hline Self-reported conservatism & 6 & -.11 & .007 & {$[-.20,-.03]$} & .01 & .795 & {$[-.09, .11]$} \\
\hline SDO & 3 & -.10 & .011 & {$[-.17,-.02]$} & .00 & .932 & {$[-.07, .08]$} \\
\hline RWA & 4 & -.07 & .073 & {$[-.14, .01]$} & .05 & 399 & {$[-.07, .18]$} \\
\hline
\end{tabular}

Note. Results for fixed effects models shown. For all effects sizes, dependent variables were residualized and continuous variables standardized.

For all effects of Partner Race and interactions with Partner Race, White partner is coded as $-1 . \dagger p<.10 . * p<.05 . * * p<.01 . * * * p<.001$.

${ }^{\text {a }}$ Indicates the number of studies included in meta-analyses. 


\section{General Discussion}

Five studies found preliminary evidence that White liberals (but not conservatives) present less competence to a Black (versus White) interaction partner. The competence downshift emerged among self-identified Democrats in Study 1, self-reported liberals in Studies 2 and 3, values-based liberals (i.e., low-RWA Whites) in Study 3, and hierarchy-based liberals (i.e., low-SDO Whites) in Study 5. These liberal Whites presented significantly less competence to a Black interaction partner than they did to a White interaction partner. Specifically, these White liberals presented less competence (Studies 2 and 3) and used fewer competence-related words (Studies 1 and 5) when responding with a Black interaction partner than with a White one. While liberals also tended to describe themselves as less competent in Study 4, though this effect did not reach significance ( $p s>.115$ ). Across all studies, shifts in White conservatives' selfpresentation of competence did not reach significance (see Study S1 for an exception, wherein conservatives engaged in a competence upshift). Ultimately, White liberals were more likely than White conservatives to present less competence to a Black (versus White) interaction partner.

Main effects of partner race emerged in Studies 1 and 2-overall, politicians (Study 1) and students (Study 2) presented significantly less competence to mostly-minority audiences than to mostly-White ones (Study 1) and to a Black interaction partner than to a White one (Study 2). This main effect, while unexpected, is compelling and does not provide evidence against the hypothesis — in these studies the competence downshift reached significance among White liberals but not White conservatives. Main effects may have emerged in these studies because they constituted conservative tests of the hypothesis. Study 1 tested self-presentation in a political context, wherein all speakers (Democrats and Republicans alike) likely wish to affiliate with minority audiences. As such, even Republicans may be more likely to engage in 
competence downshift. Study 2 tested self-presentation among students in a largely-liberal northeastern university, wherein all respondents are likely to be more liberal than the broader population. As such even relatively conservative respondents may be more likely to engage in a competence downshift. Researchers seeking to replicate and extend this work should carefully consider the contexts and sample populations that could reduce variability in affiliative interaction goals (e.g., persuasive contexts) and speaker conservatism (e.g., student samples).

The competence downshift is a subtle, but persistent effect that is unique to White liberals. The authors tend to subscribe to the notion that, while no single study can provide a conclusive answer to the "realness" of a phenomenon, a series of replications can do so more successfully. In all studies but one (Study 4), at least one indicator of conservatism revealed a significant competence downshift among liberal respondents (an exception is found in Study S1, see the Supplemental Materials for details). An internal meta-analysis revealed that, across studies, the competence downshift was significant among self-reported liberals and hierarchybased liberals. Separate examination of the effects found within each study (see Table 6) reveals that, importantly, the pattern of results is consistent across studies for each indicator of conservatism. However, no one indicator of conservatism significantly predicted a competence downshift for each study. The competence downshift reached significance among self-reported liberals in 3 out of 6 studies, among values-based liberals in 1 out of 3 studies, and among hierarchy-based liberals in 1 out of 4 studies.

The current studies examine shifts in verbal self-presentation that may be especially subtle and difficult to detect. This phenomenon merits replication and extension, as even effect sizes of small-to-moderate magnitude can have societal significance. Replication efforts should include attempts to increase power. Potential strategies include: 1) increasing the systematic variance with more extreme manipulations (e.g., expose participants to more dynamic visual stimuli such as photographs, video, or face-to-face interactions with Black or White 
confederates), 2) reducing random error with a repeated measures design (i.e., expose participants to both a White and Black interaction partner, test within-subject differences), or 3) reducing random error with increased sample sizes. As an exploratory step, we conducted power analyses to determine the sample size required to detect the effects found for each conservatism measure based on the results of the internal meta-analysis. A priori sample size calculation (G*Power (Faul, Erdfelder, Buchner, \& Lang, 2009), point biserial model, $\alpha=.05,90 \%$ power) revealed the following total sample requirements to detect the effects found among White liberals for each conservatism measure: 805 participants (self-reported liberals), 1146 participants (hierarchy-based liberals), and 2271 participants (values-based liberals). The authors hope that other researchers make efforts to replicate and extend this work, and caution them to strongly consider the time and resources required to recruit the participants necessary to reliably detect the competence downshift as found across these studies.

The demographics of MTurk samples are significantly more population-representative than those of other convenience samples, such as college students (Berinsky et al., 2012; Buhrmester et al., 2011; Casler et al., 2013; Mason \& Suri, 2012; Paolacci, Chandler, \& Ipeirotis, 2010)). Nonetheless, one could question the generalizability of the competence downshift, tested experimentally with social scenarios that featured hypothetical Black or White interaction partners (Studies $2-4$ ) and an ostensibly real but still online interaction partner (Study 5). However, Study 1 provided initial evidence of the competence downshift in real-word speech, addressing the generalizability of the competence downshift by examining political campaign speeches from White Democratic or Republican presidential candidates that were addressed to mostly-White versus mostly-minority audiences. Although Democratic candidates tended to speak to minority audiences more often than did Republicans (at least according to this search for such speeches), Democratic candidates more so than Republicans presented less competence to mainly-minority audiences than to mostly-White audiences. Indeed, liberal White 
politicians have presented less competence to minority audiences than to White audiences over the course of decades.

White liberals did not show significant changes in warmth based on the race of an interaction partner, suggesting that the competence-based stereotypes applied to Blacks may drive these changes in liberals' self-presentation. Collectively, these studies suggest that, for those Whites who are more affiliative toward minorities - that is, liberals - stereotypes may play a role in the impression management strategies utilized affiliation attempts, relating to a wellintentioned, but ultimately patronizing competence downshift.

Liberals did not engage in this competence downshift explicitly. Across studies, White liberals did not admit to a desire to appear less competent (or more warm) with a Black partner than with a White one. A notable exception includes Study 5, wherein liberals across conservatism measures reported having the goal to appear less competent to a Black interaction partner than to a White one. This finding highlights the covert nature of the competence downshift strategy.

Finally, Study 5 revealed a discrepancy between verbal self-presentation of competence and perceived affiliation goals. As noted, hierarchy-based liberals displayed a difference in the competence presented to a Black (versus White) interaction partner: presenting less competence to Black partners than they did to White partners. Their conservative counterparts showed no such difference in their own verbal self-presentation. However, judges blind to presenter conservatism and partner race perceived such liberals to be the egalitarian ones - that is, wishing to affiliate equally with a Black or a White partner - and conservatives to be the discriminatory ones - that is, wishing to affiliate with a Black partner less than with a White one. Not only do White liberals engage in a competence downshift (Studies 1-3,5) and report wishing to be seen as less competent by a Black partner than by a White one (Study 5), but they also are viewed as more egalitarian than their conservative counterparts by third-party observers. 


\section{Future Directions}

Prior research has rarely examined self-presentation across racial lines, and this research constitutes the first investigation of the moderating role that individual differences in sociopolitical preferences and beliefs may play in impression management in intergroup settings. These studies provide a first step by illuminating impression management strategies used in interracial contexts by Whites who vary in self-reported conservatism and the two most wellresearched measures of socio-political conservatism (i.e., SDO and RWA). However, as this research constitutes a preliminary examination of a novel phenomenon, future research is needed to refine and expand up on the current findings.

First, future research is needed to determine when different types of liberals will engage in the competence downshift. The current work provides initial evidence that self-identified Democrats (in Study 1), self-reported liberals (in Studies 2 and 3), values-based liberals (in Study 3), and hierarchy-based liberals (in Study 5) do engage in a competence downshift toward racial minorities. However, while the effect was in the predicted direction across all indicators of conservatism in Studies 1-5, no one measure of socio-political conservatism significantly predicted the competence downshift in each study. That being said, meta-analysis revealed that, across studies, self-identified liberalism-conservatism most reliably predicted liberals' competence downshift. Furthermore, Study 1 reveals that, when the stakes are high enough (as they are in a presidential campaign), membership in the liberal political party is enough to predict the use of this self-presentational response. However, the conditions under which a certain type of conservatism will predict this phenomenon remain unclear.

Second, further work needs to delve deeper into the proposed mechanisms that drive the competence downshift as expressed by White liberals. Overall, liberals' (specifically, selfreported liberals' and hierarchy-based liberals') self-presentation of competence, rather than warmth, significantly differed based on partner race. This is likely due to stereotypes 
differentiating Blacks from Whites, which fall in the dimension of competence. Previous research indicates that Whites are aware that Blacks and Latinos are characterized as less intelligent than higher status groups (Devine \& Elliot, 1995; Fiske et al., 2002; Krueger, 1996; Weaver, 2007). Furthermore, members of high-status groups tend to believe that they are considered racist by minorities (Vorauer et al., 1998), which may give them the goal of appearing warm during intergroup interactions (Bergsieker et al., 2010). While the current explanation for the competence downshift holds theoretical and empirical merit, further research, is needed to detangle these two proposed mechanisms: the desire to affiliate, and the use of stereotypes to do so.

Examining awareness of the competence downshift as an impression management response may provide insight on the causal mechanisms that explain this response. While hierarchy-based conservatives anticipated being seen as more competent by a Black partner than by a White one, hierarchy-based liberals anticipated being seen as (non-significantly) less competent by a Black partner than by a White one (Study 5). These liberals may recognize their chosen self-presentational response - and believe that it was make them appear less stereotypically high in status to a Black partner. This could provide initial evidence of the strategic nature of the liberals' competence downshift. However, open questions remain. To what extent does each factor - the desire to affiliate with minorities and the use of stereotypical knowledge to do so- explain the use of a competence downshift strategy? What additional factors may be involved in this likely well-meaning but ultimately patronizing behavior? These constitute intriguing questions for future research.

Furthermore, future research might further examine boundary conditions of the competence downshift phenomenon. Familiarity with a minority partner may constitute one such boundary condition, attenuating the competence downshift for liberal Whites, as they rely less on stereotypes. Given that liberals are more open to relationships with Blacks (Eastwick, Richeson, 
Son, \& Finkel, 2009; Yancey, 2007), familiarity with a Black partner may reduce the patronizing behavior shown in these studies by decreasing liberal Whites' reliance on stereotypes as a method of affiliation.

Whites' self-presentation toward other ethnic outgroup members may reveal an additional boundary condition. Do liberals present less competence to outgroups that are not stereotyped as less competent than Whites (e.g., Asian-Americans)? Following up on this possibility, researchers may find that White liberals may present less warmth to this particular outgroup, as Asians are often stereotyped as being colder (though no less intelligent) than Whites (Fiske, Cuddy, Glick, \& Xu, 2002; Lin, Kwan, Cheung, \& Fiske, 2005). Such a finding would provide further support for a stereotyping explanation of the effects found in the current work. If, however, White liberals do engage in a competence downshift toward Asian-American interaction partners, that would suggest a compensation effect (Holoien \& Fiske, 2017) may be at play_-in efforts to affiliate (i.e., appear warmer) to any outgroup member, White liberals use the general impression management strategy of downplaying their competence.

Finally, future work would do well to examine the second reliable pattern effect found in the current work: across studies, White liberals tended to present more competence to a White interaction partner than did White conservatives. This second simple effect was not predicted. A stereotyping explanation may also apply here. In this case, White liberals may label other Whites as more competent than do White conservatives, prompting them to upshift their competence in the presence of other Whites relative to their more conservative counterparts. Future research is needed to replicate and further examine this possibility.

\section{Limitations}

These studies are not without limitations. Though the paper currently frames the shift in competence as an outgroup-focused competence downshift, this could also be viewed as an ingroup-focused competence upshift. Future tests of the competence downshift should include a 
baseline condition, wherein no name or avatar is given for the partner at all. These baseline selfpresentation results can then be compared to those in the racial ingroup or outgroup partner conditions, shedding more light on how an ingroup or outgroup interaction partner can affect self-presentation of warmth or competence. Whites, however, tend to most commonly interact with other Whites (McPherson, Smith-Lovin, \& Cook, 2000; Rugh \& Massey, 2013), so quite likely such a baseline target would be assumed to be White. For this reason, the current research approaches these findings as an outgroup-focused competence downshift.

Furthermore, race is often confounded with status; as such, the use of stereotypically White or stereotypically Black names may bolster this confound. Study 5 began to address this issue using White or Black avatars in addition to less obviously stereotypical names. Additionally, Study 1 provided evidence of the competence downshift in a real-world setting, without the use of stereotypically Black names. However, future studies attempting to replicate the competence downshift may consider using visual images exclusively to reduce the potential confound of status.

\section{Conclusion}

In many ways, America is becoming a more egalitarian nation. Whites show increased support for minority political candidates (Garcia \& Tate, 2013; Tesler \& Sears, 2010), indicate more positive sentiments toward social policies that benefit minorities (Bobo, 2001), and express less explicit prejudice against outgroups (Bergsieker, Leslie, Constantine, \& Fiske, 2012; Devine \& Elliot, 1995; Dovidio \& Gaertner, 1986; Fiske, 2002). However, recent research has scarcely examined the more interpersonal level of self-presentation across racial lines. Despite the progress toward egalitarian goals, indirect indicators of bias remain, along with negative stereotypes that characterize minorities as less intelligent than Whites. Although the nation as a whole has shown a degree of progress in recent decades, individual variability in holding egalitarian socio-political attitudes remains. Ironically, those who are less explicitly antagonistic 
toward minorities may be more likely to display such indirect forms of bias, drawing on negative stereotypes to affiliate with Blacks. 


\section{References}

Abele, A. E., Hauke, N., Peters, K., Louvet, E., Szymkow, A., \& Duan, Y. (2016). Facets of the fundamental content dimensions: Agency with competence and assertivenessCommunion with warmth and morality. Frontiers in Psychology, 7, 1-17.

Abele, A. E., \& Wojciszke, B. (2007). Agency and communion from the perspective of self versus others. Journal of Personality and Social Psychology, 93, 751-763.

Adorno, T. W., Frenkel-Brunswik, E., Levinson, D. J., \& Sanford, R. N. (1950). The authoritarian personality. Oxford, England: Harpers.

Allport, G. W. (1954). The nature of prejudice. Cambridge, MA: Addison-Wesley.

Altemeyer, B. (1981). Right-wing authoritarianism. Winnipeg, Manitoba, Canada: University of Manitoba Press.

Altemeyer B. (1988). Enemies of freedom: Understanding right-wing authoritarianism. San Francisco, CA: Jossey-Bass.

Altemeyer B. (1996). The authoritarian specter. Cambridge, MA: Harvard University Press. Altemeyer, B. (1998). The other "authoritarian personality.” In M. Zanna (Ed.), Advances in experimental social psychology (Vol. 30, pp. 47-92). San Diego: Academic.

Altemeyer, R. (2006). The authoritarians. Lulu. http://home.cc.umanitoba.ca/*altemey/.

Aron, A., Aron, E. N., \& Smollan, D. (1992). Inclusion of Other in the Self Scale and the structure of interpersonal closeness. Journal of Personality and Social Psychology, 63, 596-612.

Asbrock, F., Christ, O., Duckitt, J., \& Sibley, C. G. (2012). Differential effects of intergroup contact for authoritarians and social dominators: A dual process model perspective. Personality And Social Psychology Bulletin, 38(4), 477-490.

Banaji, M. R., \& Heiphetz, L. (2010). Attitudes. In S. T. Fiske, D. T. Gilbert, \& G. Lindzey (Eds.). Handbook of social psychology, Vol 1 (5th ed.) (pp. 353-393). Hoboken, NJ, US: 
John Wiley \& Sons Inc.

Bergsieker, H. B., Leslie, L. M., Constantine, V. S., \& Fiske, S. T. (2012). Stereotyping by omission: Eliminate the negative, accentuate the positive. Journal of Personality and Social Psychology, 102(6), 1214-1238.

Bergsieker, H., Shelton, J. N., \& Richeson, J. A. (2010). To be liked versus respected: Divergent goals in interracial interactions. Journal of Personality and Social Psychology,99, 248264.

Berinsky, A. J., Huber, G. A., and Lenz, G. S. (2012). Evaluating online labor markets for experimental research: Amazon.com's mechanical turk. Political Analysis, 20(3), 351368.

Bertrand, M., \& Mullainathan, S. (2004). Are Emily and Greg more employable than Lakisha and Jamal? A field experiment on labor market discrimination. American Economic Review, 94(4), 991-1013.

Bobo, L. (2001). Racial attitudes and relations at the close of the twentieth century. In America becoming: Racial trends and their consequences (Vol. 1, pp. 264-301). Washington, DC: National Academy Press.

Buhrmester, M., Kwang, T., \& Gosling, S. D. (2011). Amazon's Mechanical Turk: A new source of inexpensive, yet high-quality, data?. Perspectives On Psychological Science, 6(1), 3-5.

Casler, K., Bickel, L., \& Hackett, E. (2013). Separate but equal? A comparison of participants and data gathered via Amazon's MTurk, social media, and face-to-face behavioral testing. Computers in Human Behavior, 29, 2156-2160.

Crawford J. T., Jussim L., Cain T. R., Cohen F. (2013). Right-wing authoritarianism and social dominance orientation differentially predict biased evaluations of media reports. Journal of Applied Social Psychology, 43, 163-174 
Croft, A., \& Schmader, T. (2012). The feedback withholding bias: Minority students do not receive critical feedback from evaluators concerned about appearing racist. Journal Of Experimental Social Psychology, 48(5), 1139-1144.

Devine, P. G., \& Elliot, A. J. (1995). Are racial stereotypes really fading? The Princeton trilogy revisited. Personality and Social Psychology Bulletin, 21, 1139-1150.

Dovidio, J. F., \& Gaertner, S. L. (1986). Prejudice, discrimination, and racism. San Diego, CA, US: Academic Press.

Dovidio, J. F., \& Gaertner, S. L. (2000). Aversive racism and selection decisions: 1989 and 1999. Psychological Science, 11(4), 315-319.

Dovidio, J. F., Kawakami, K., \& Gaertner, S. L. (2002). Implicit and explicit prejudice and interracial interaction. Journal of Personality and Social Psychology, 82(1), 62-68.

Druckman, J. N., \& Kam, C. D. (2011). Students as Experimental Participants: A Defense of the 'Narrow Data Base. In J. N. Druckman, D. P. Green, J. H. Kuklinski, \& A. Lupia (Eds.), Cambridge Handbook of Experimental Political Science, New York: Cambridge University Press.

Duckitt, J. (2001). A dual-process cognitive-motivational theory of ideology and prejudice. In M. P. Zanna, M. P. Zanna (Eds.), Advances in experimental social psychology, Vol. 33 (pp. 41-113). San Diego, CA, US: Academic Press.

Duckitt, J., Wagner, C., du Plessis, I., \& Birum, I. (2002). The psychological bases of ideology and prejudice: Testing a dual process model. Journal Of Personality And Social Psychology, 83(1), 75-93

Eastwick, P. W., Richeson, J. A., Son, D., \& Finkel, E. J. (2009). Is love colorblind? Political orientation and interracial romantic desire. Personality and Social Psychology Bulletin, $35(9), 1258-1268$.

Faul, F., Erdfelder, E., Lang, A. G., \& Buchner, A. (2007). G*Power 3: A flexible statistical 
power analysis program for the social, behavioral, and biomedical sciences. Behavior Research Methods, 39, 175-191.

Fazio, R. H., \& Olson, M. A. (2003). Implicit measures in social cognition research: Their meaning and uses. Annual Review of Psychology, 54, 297-327.

Field, A. P. (2003). The problems in using fixed-effects models of meta-analysis on real-world data. Understanding Statistics, 2, 77-96.

Field, A. P., \& Gillett, R. (2010). How to do a meta-analysis. British Journal of Mathematical and Statistical Psychology, 63, 665-694.

Fiske, S. T. (2002). What we know about bias and intergroup conflict, the problem of the century. Current Directions In Psychological Science, 11(4), 123-128.

Fiske, S. T., Cuddy, A. C., \& Glick, P. (2007). Universal dimensions of social cognition: Warmth and competence. Trends In Cognitive Sciences, 11(2), 77-83.

Fiske, S. T., Cuddy, A. J. C, Glick, R, \& Xu, J. (2002). A model of (often mixed) stereotype content: Competence and warmth respectively follow from perceived status and competition, Journal of Personality and Social Psychology, 82, 878-902.

Fiske, S. T., Cuddy, A. J. C., \& Glick, P. (2007). Universal dimensions of social cognition: Warmth and competence. Trends in Cognitive Sciences, 11, 77-83.

Fiske, S.T., Dupree, C. H., Nicolas, G., \& Swencionis, J. K. (2016). Status, power, and intergroup relations: The personal is the societal. Current Opinion in Psychology, 11, 4448.

Flesch, R. (1948). A new readability yardstick. Journal of Applied Psychology, 32, 221-233.

Fryer, R. G. J., \& Levitt, S. D. (2004). The causes and consequences of distinctively Black names. Quarterly Journal of Economics, 119(3), 767-805.

Garcia, J. R., \& Tate, K. (2013). Race, ethnicity, and politics: Controversies and new directions. In R. J. La Raja (Eds.), New directions in American politics. New York: Routledge. 
Gaucher, D., Friesen, J., \& Kay, A. C. (2011). Evidence that gendered wording in job advertisements exists and sustains gender inequality. Journal Of Personality And Social Psychology, 101(1), 109-128.

Gilens, M. (1996). Race and poverty in America: Public misperceptions and the American news media. Public Opinion Quarterly, 60(4), 515-541.

Goh, J. X., Hall, J., \& Rosenthal, R. (2016). Mini meta-analysis of your own studies: Some arguments on why and a primer on how. Social and Personality Psychology Compass, 10(10), 535-549..

Goffman, E. (1959). The presentation of self in everyday life. Garden City, NY: Doubleday/Anchor Books.

Graham, J., Haidt, J., \& Nosek, B. A. (2009). Liberals and conservatives rely on different sets of moral foundations. Journal Of Personality And Social Psychology, 96(5), 1029-1046.

Gravetter, F., \& Wallnau, L. (2014). Essentials of statistics for the behavioral sciences (8th ed.). Belmont, CA: Wadsworth.

Greenwald, A. G., McGhee, D. E., \& Schwartz, J. K. (1998). Measuring individual differences in implicit cognition: The implicit association test. Journal Of Personality And Social Psychology, 74(6), 1464-1480.

Hedges, L. V., \& Vevea, J. L. (1998). Fixed- and random-effects models in meta-analysis. Psychological Methods, 3, 486-504.

Ho, A. K., Sidanius, J., Cuddy, A. J., \& Banaji, M. R. (2013). Status boundary enforcement and the categorization of Black-White biracials. Journal Of Experimental Social Psychology, 49(5), 940-943.

Ho, A. K., Sidanius, J., Pratto, F., Levin, S., Thomsen, L., Kteily, N., \& Sheehy-Skeffington, J. (2012). Social dominance orientation: Revisiting the structure and function of a variable 
THE COMPETENCE DOWNSHIFT BY WHITE LIBERALS

predicting social and political attitudes. Personality and Social Psychology Bulletin, 38, $583-606$.

Holoien, D. S., \& Fiske, S. T. (2013). Downplaying positive impressions: Compensation between warmth and competence in impression management. Journal of Experimental Social Psychology, 49(1), 33-41.

Jones, E. E., \& Pittman, T. (1982). Toward a general theory of strategic self-presentation. In J. Suls (Ed.), Psychological perspectives on the self, Vol. 1. (pp. 231-262). Hillsdale, NJ: Lawrence Erlbaum Associates, Inc.

Jost, J. T., Banaji, M. R., \& Nosek, B. A. (2004). A Decade of System Justification Theory: Accumulated Evidence of Conscious and Unconscious Bolstering of the Status Quo. Political Psychology, 25(6), 881-919.

Jost, J. T., Glaser, J., Kruglanski, A. W., \& Sulloway, F. J. (2003). Political conservatism as motivated social cognition. Psychological Bulletin, 129, 339 -375.

Katz, D., \& Braly, K. (1933). Racial stereotypes of one hundred college students. The Journal Of Abnormal And Social Psychology, 28(3), 280-290.

Kervyn, N., Fiske, S. T., \& Yzerbyt, V. (2015). Forecasting the Primary Dimension of Social Perception: Symbolic and Realistic Threats Together Predict Warmth in the Stereotype Content Model. Social Psychology, 46(1), 36-45.

Kincaid J.P., Fishburne, R.P, Rogers, R.L., \& Chissom, B.S. (1975). Derivation of new readability formulas (Automated Readability Index, Fog Count and Flesch Reading Ease Formula) for Navy-enlisted personnel. Research Branch Report 8-75. Millington, TN: Naval Technical Training, U.S. Naval Air Station; Memphis, TN.

Knowles, E. D., Lowery, B. S., Hogan, C. M., \& Chow, R. M. (2009). On the malleability of ideology: Motivated construals of color blindness. Journal Of Personality And Social Psychology, 96(4), 857-869. 
Krueger, J. (1996). Personal beliefs and cultural stereotypes about racial characteristics. Journal of Personality and Social Psychology, 71(3), 536-538.

Kteily, N., Cotterill, S., Sidanius, J., Sheehy-Skeffington, J., \& Bergh, R. (2014). 'Not one of us': Predictors and consequences of denying ingroup characteristics to ambiguous targets. Personality And Social Psychology Bulletin, 40(10), 1231-1247.

Leach, C. W., Ellemers, N., \& Barreto, M. (2007). Group virtue: The importance of morality (vs. competence and sociability) in the positive evaluation of in-groups. Journal of Personality and Social Psychology, 93, 234-249.

Leary, M. R. (1995). Self-presentation: Impression management and interpersonal behavior. Boulder, CO: Westview Press.

Lin, M. H., Kwan, V. Y., Cheung, A., \& Fiske, S. T. (2005). Stereotype Content Model Explains Prejudice for an Envied Outgroup: Scale of Anti-Asian American Stereotypes. Personality And Social Psychology Bulletin, 31(1), 34-47.

Lydon, J. E., Jamieson, D. W., \& Zanna, M. P. (1988). Interpersonal similarity and the social and intellectual dimensions of first impressions. Social Cognition, 6(4), 269-286.

Mason, W., \& Suri, S. (2012). Conducting behavioral research on Ama- zon's Mechanical Turk. Behavior Research Methods, 44, 1-23.

McPherson, M., Smith-Lovin, L., \& Cook, J. M. (2001). Birds of a feather: Homophily in social networks. Annual Review of Psychology, 27, 415-444.

Mendes, W. B., \& Koslov, K. (2013). Brittle smiles: Positive biases toward stigmatized and outgroup targets. Journal Of Experimental Psychology: General, 142(3), 923-933.

Nezlek, J. B., Schu `z, A., \& Sellin, I. (2007). Self-presentation success in daily social interaction. Self and Identity, 6, 361-379.

Paolacci, G., Chandler, J., \& Ipeirotis, P. G. (2010). Running experiments on Amazon Mechanical Turk. Judgment and Decision Making, 5, 411- 419. 
Peeters, G. (2001). In search for a social-behavioral approach-avoidance dimension associated with evaluative trait meanings. Psychologica Belgica, 41(4), 187-203.

Pennebaker, J. W., Booth, R. J., Boyd, R. L., \& Francis, M. E. (2015). Linguistic Inquiry and Word Count: LIWC2015 [Computer software]. Austin, TX: Pennebaker Conglomerates (www.LIWC.net).

Pennebaker, J. W., Booth, R. J., \& Francis, M. E. (2007). Linguistic Inquiry and Word Count: LIWC 2007 [Computer software]. Austin, TX: LIWC.

Peterson, R. A. (2001). On the use of college students in social science research: Insights from a second-order meta-analysis. Journal of consumer research, 28(3), 450-461.

Pew Research Center. (2014). Religious Landscape Survey.

Pratto, F., Sidanius, J., Stallworth, L. M., \& Malle, B. F. (1994). Social dominance orientation: A personality variable predicting social and political attitudes. Journal of Personality and Social Psychology, 67, 741-763.

Richeson, J. A., \& Shelton, J. N. (2007). Negotiating interracial interactions: Costs, consequences, and possibilities. Current Directions In Psychological Science, 16(6), 316320.

Rokeach, M. (1973). The nature of human values. New York, NY, US: Free Press.

Rosenfeld, P. R., Giacalone, R. A. \& Riordan, C. A. (1995). Impression management in organizations: Theory, measurement, and practice. New York: Routledge.

Rudman, L. A., \& Kilianski, S. E. (2000). Implicit and explicit attitudes toward female authority. Personality And Social Psychology Bulletin, 26(11), 1315-1328.

Rugh, J. S., \& Massey, D. S. (2010). Racial segregation and the American foreclosure crisis. American Sociological Review, 75(5), 629-651.

Russell, A. T., \& Fiske, S. T. (2008). It's all relative: Competition and status drive interpersonal perception. European Journal Of Social Psychology, 38(7), 1193-1201. 
Schlenker, B. R., \& Pontari, B. A. (1973). The strategic control of information: Impression management and self-presentation in daily life. In A. Tesser, R. B. Felson, \& J. M. Suls (Eds.), Psychological perspectives on self and identity (pp. 199-232). Washington, DC: American Psychological Association.

Scopelliti, I., Loewenstein, G., \& Vosgerau, J. (2015). You call it 'self-exuberance'; we call it 'bragging': Miscalibrated predictions of emotional responses to self-promotion. Psychological Science, 26(6), 903-914.

Shelton, J. N. (2003). Interpersonal concerns in social encounters between majority and minority group members. Group Processes \& Intergroup Relations, 6(2), 171-185.

Shelton, J. N., \& Richeson, J. A. (2006). Interracial interactions: A relational approach. In M. P. Zanna (Ed.), Advances in experimental social psychology, Vol 38 (pp. 121-181). San Diego, CA US: Elsevier Academic Press.

Shelton, J. N., West, T. V., \& Trail, T. E. (2010). Concerns about appearing prejudiced: Implications for anxiety during daily interracial interactions. Group Processes \& Intergroup Relations, 13(3), 329-344.

Sidanius, J., \& Pratto, F. (1999). Social dominance: An intergroup theory of social hierarchy and oppression. New York, NY: Cambridge University Press.

Silverman, D. (1993). Interpreting qualitative data: Methods for analyzing talk, text and interaction. London: Sage.

Sinclair, S., Lowery, B. S., Hardin, C. D., \& Colangelo, A. (2005). Social Tuning of Automatic Racial Attitudes: The Role of Affiliative Motivation. Journal Of Personality And Social Psychology, 89(4), 583-592.

Smith, J. (Ed.). (2009). Well said! Great speeches in American history. Washington, DC: E \& K Publishing.

Swencionis, J. K., \& Fiske, S. T. (2016). Promote up, ingratiate down: Status comparisons drive 
warmth-competence tradeoffs in impression management. Journal of Experimental Social Psychology, 64, 27-34.

Tesler, M. \& Sears, D. O. (2010). Obama's Race: The 2008 Election and the Dream of a Post-Racial America. Chicago: University of Chicago Press.

Thomsen, L., Green, E. T., \& Sidanius, J. (2008). We will hunt them down: How social dominance orientation and right-wing authoritarianism fuel ethnic persecution of immigrants in fundamentally different ways. Journal Of Experimental Social Psychology, $44(6), 1455-1464$.

Thorndike, E. L. (1920). A constant error on psychological rating. Journal of Applied Psychology, 4, 25-29.

Trochim, W. M., \& Donnelly, J. P. (2006). The research methods knowledge base (3rd ed.). Cincinnati, OH: Atomic Dog.

Vorauer, J. D., Hunter, A. J., Main, K. J., \& Roy, S. A. (2000). Meta-stereotype activation: Evidence from indirect measures for specific evaluative concerns experienced by members of dominant groups in intergroup interaction. Journal Of Personality And Social Psychology, 78(4), 690-707.

Vorauer, J. D., Main, K. J., \& O’Connell, G. B. (1998). How do individuals expect to be viewed by members of lower status groups? Content and implications of metastereotypes. Journal of Personality and Social Psychology, 75, 917-937.

Wayne, S. J., \& Ferris, G. R. (1990). Influence tactics, affect, and exchange quality in supervisor-subordinate interactions: A laboratory experiment and field study. Journal Of Applied Psychology, 75(5), 487-499.

Weaver, C. N. (2007). The effects of contact on the prejudice between Hispanics and nonHispanic Whites in the United States. Hispanic Journal of Behavioral Sciences, 29, 254 274. 
Wilson, D. B. (2005). Meta-analysis macros for SAS, SPSS, and Stata [Computer software]. Retrieved from http://mason.gmu.edu/ dwilsonb/ma.html

Wojciszke, B. (1994). Multiple meanings of behavior: Construing actions in terms of competence or morality. Journal Of Personality And Social Psychology, 67(2), 222-232.

Wojciszke, B. (1997). Parallels between competence- versus morality-related traits and individualistic versus collectivistic values. European Journal Of Social Psychology, 27(3), 245-256.

Wojciszke, B. (2005). Morality and competence in person- and self-perception. In W. Stroebe (Ed.), European review of social psychology (Vol. 16, pp. 155-188). Hove, United Kingdom: Psychology Press.

Wojciszke, B., Bazinska, R., \& Jaworski, M. (1998). On the dominance of moral categories in impression formation. Personality And Social Psychology Bulletin, 24(12), 1251-1263.

Yancey, G. (2007). Homogamy over the net: Using Internet advertisements to discover who interracially dates. Journal of Social and Personal Relationships, 24, 913-930. 